Yayın Geliş Tarihi: 29.07.2020

Yayına Kabul Tarihi: 24.12.2021

Online Yayın Tarihi: 31.12.2021

http://dx.doi.org/10.16953/deusosbil.775669
Dokuz Eylül Üniversitesi Sosyal Bilimler Enstitüsü Dergisi Cilt: 23, Say1: 4, Y11: 2021, Sayfa: 1543-1588 ISSN: 1302-3284 E-ISSN: 1308-0911

Derleme Makalesi

\title{
E-POSTA PAZARLAMASI ALANINDA 1950-2019 YILLARI ARASINDA YAPILAN ÇALIȘMALARA YÖNELİK BİR ŞEMATIK YAZIN TARAMASI
}

\author{
Canberk CETIN* \\ Muhammet Ali TILLTAY $Y^{* *}$
}

$\ddot{O} z$

E-posta pazarlaması internetin gelişimi ile ortaya çıkan elektronik bir pazarlama aracı olarak literatürde yer almaktadır. Şematik yazın taraması (mapping review) olarak gerçekleştirilen bu çalışmanın amacı, pazarlama aracı olarak ele alınan e-posta pazarlaması alanına dair bir öngörü sağlanmasıdır. Çalışmada 1950-2019 yılları arasında uluslararası akademik dergilerde yer alan pazarlama odaklı 57 e-posta pazarlaması çalışması incelenmiştir. Çalışmaların seçiminde anahtar kelimeler kullanılarak filtreleme gerçekleştirilmiş, doğrudan ilgili alana ve pazarlamaya yönelik olmayan çalışmalar kapsam dışında bırakılmıştır. İncelenen çalışmalar ile e-posta pazarlamasının teorik arka planınına, odaklandığl alanlara, ele alındiğg sektörlere ve çalışmaların yönelimlerine dair sonuçlar elde edilmiştir. Incelenen çalıșmaların 42 'si ampirik, 15'i ise kavramsaldır. En çok çalıșllan alanın tüketici davranışları olduğuna, en fazla sayıda yayının "Journal of Direct, Data and Digital Marketing Practice” dergisinde yer aldiğına ve 2016 yılının 11 çalışma ile ilgili literatürde en çok yayının yapıldı̆̆ yıl olduğu sonucuna ulaşılmıştır. Çalışmada elde edilen sonuçlar ile farkl bir alana yönelmek isteyen akademisyenlere niş bir alan önerisi sunularak, e-posta pazarlaması literatüründe ele alınmamış olan alanlar gösterilmektedir.

Anahtar Kelimeler: E-posta, E-posta pazarlaması, E-posta pazarlaması literatür taraması, şematik yazın taraması

Bu makale için önerilen kaynak gösterimi (APA 6. Sürüm):

Çetin, C., Tiltay, M. A. (2021). E-posta pazarlaması alanında 1950-2019 yılları arasında yapılan çalışmalara yönelik bir şematik yazın taraması. Dokuz Eylül Üniversitesi Sosyal Bilimler Enstitüsü Dergisi, 23 (4), 1543-1587.

* Dr. Öğrencisi, Eskişehir Osmangazi Üniversitesi, Sosyal Bilimler Enstitüsü, İşletme Bölümü, ORCID: 0000-0003-0755-2601, canberkcetin@gmail.com.

* Doç. Dr., Eskişehir Osmangazi Üniversitesi, İktisadi ve İdari Bilimler Fakültesi İşletme Bölümü, ORCID: 0000-0001-7877-8523, matiltay@gmail.com. 


\title{
A MAPPING REVIEW OF STUDIES IN THE FIELD OF E-MAIL MARKETING BETWEEN 1950 AND 2019
}

\begin{abstract}
E-mail marketing is included in the literature as an electronic marketing tool that emerges with the development of the internet. The puspose of this study, carried out as a mapping review, is to provide an insight into the field of e-mail marketing, which is considered as a marketing tool. In the study, 57 marketing focused e-mail marketing studies in international academic journals between 1950-2019 were examined. In the selection of the studies, filtering was carried out using keywords, and studies not directly related to the field and marketing were excluded. With the studies examined, results were obtained regarding the theoretical background of e-mail marketing, the areas it focuses on, the sectors it is addressed, and the orientations of the studies. 42 of the studies examined are empirical and 15 are conceptual. It has been concluded that the most studied area is consumer behavior, the highest number of publications are included in the journal "Journal of Direct, Data and Digital Marketing Practice" and that 2016 is the year in which the most publications were made in the literatüre related to 11 studies. With the results obtained in the study, a niche field proposal is presented to academicians who want to move to a different area, and the areas not covered in the e-mail marketing literature are shown.
\end{abstract}

Keywords: E-mail, E-mail marketing, E-mail marketing literature review, Mapping review

\section{Gİiş}

Elektronik pazarlama ürün veya hizmetlerin satıcıdan alıcıya elektronik metotlar aracılığıyla medya ile ulaştırılmasını içermektedir. Elektronik pazarlama, 19.yy'da telgrafin kullanılması ile başlamışıır. Ardından telefonun, radyonun ve televizyonun yaygınlaşması ile elektronik medya etkin bir pazarlama gücü haline gelmiştir (Hoge, 1993). Teknolojideki elektronik gelişmeler ile internetin ortaya çıkması ve hızlı bir şekilde yayılması akademik toplulukta büyük bir ilgi yaratmıștır (Pomirleanu vd., 2013). Yıllar içerisinde internetin daha fazla işletme tarafindan kullanılması işletmelerin etkililiklerini yükseltmiştir. Elektronik ortamlarda yaratılan pazarlar ise alıcıların ve satıcıların birbirlerine ulaşmalarında büyük bir kolaylık sağlayarak internetin pazarlama, satış ve dağıtım kanalına evrilmesine katkı sağlamıştır (Farhoomand \& Lovelock, 2001). Elektronik ortamlarda alıcı ve satıcı arasındaki iletişimin gerçekleşmesini sağlayan araçlardan biri de e-postadır. 2019 yılı itibariyle günlük ortalama 296 milyar e-postanın gönderilmesi (Statista, 2020), ele alınan aracın kapsamının ne denli geniş olduğunu göstermektedir. E-postanın geniş kitleler tarafından benimsenmesi toplumu ve ticareti büyük ölçüde etkileyerek, bireylerin birbirleri ile kişisel düzeyde kurdukları iletişimle beraber işletmelerin de müşterileri ile kurdukları iletişimlerin şeklini değiştirmiştir (O'Connor, 2008). Günümüzde işletmeler için e-posta, pazarlama stratejisinde önemli bir konumda bulunarak, promosyonların ve hizmet beklentilerinin iletiminde, satışların arttırılmasında, yeni müşteri edinmede ve varolan müşteriler ile iletişimleri 
sürdürmede kullanılmaktadır (DeFrene vd., 2005). DMA (2019) verilerine göre işletmeler tarafindan e-posta pazarlaması üzerine gerçekleştirilen 1 \$'lık harcama ile yaklaşık 42 ' lık bir kazanç sağlanmaktadır. Sahip olduğu yüksek getiri dönüşü eposta pazarlamasını uygun maliyetli ve verimli bir araç haline getirmektedir. Küçük ve orta ölçekteki işletmeler için ise e-posta pazarlamasının tüketicilere ulaşma noktasında büyük katkıları vardır. $\% 80$ geri dönüş oranı sağlayarak, işletmelerin büyümelerine büyük katkıda bulunduğu ifade edilmektedir (Emarsys, 2018). Bu veriler ile e-posta pazarlamasının özellikle küçük ve orta ölçekteki işletmeler için önemi de açıkça görülmektedir.

E-posta pazarlaması, müşteri ilişkilerinde, pazarlama stratejilerinde, iç ve dış iletişimde kullanılan çevrim içi araçlardan biri olarak konumlanmaktadır. İşletmeler ve tüketiciler için büyük katkıları olan, popüler ve önemli bir araç olmasına rağmen e-posta pazarlaması alanında gerçekleştirilmiş şematik bir literatür taraması bulunmamaktadır. Şematik literatür taraması ile e-posta pazarlaması literatüründeki boşlukları tablolar, grafikler ve sayılarla belirleyerek literatürün haritasını çıkarmak sonraki çalışmalar için önem taşımaktadır. Bu çalışma ile e-posta pazarlaması alanında çalışmak isteyen araştırmacılara alana dair açık ve şeffaf bir içgörü sunulmaktadır. Bu doğrultuda gerçekleştirilen şematik yazın taraması (mapping review) ile e-posta pazarlaması alanı incelenerek literatürde yer alan çalışmaların sayıları, yöntemleri, analiz birimleri, yer aldığı dergiler incelenerek ve alandaki boşluklar belirlenerek, tablo ve grafikler aracıllğıyla ilgili literatüre dair bir öngörü sağlanmıştır.

\section{E-POSTA PAZARLAMASI}

İnternetin icadı ile pazarlama alanında yeni bir iletişim kanalı ortaya çıkmıştır. Oluşan bu yeni kanal sunduğu etkileşim ortamıyla yalnızca bireyler arası iletişimde değil, işletmelerin müşterileri ile olan iletişimlerinde de etkili olmuştur. Değişen iletişim şekli, işletmelerin müşterileri ile olan iletişim stratejilerini güncellemelerini gerektirmiştir. İşletmeler tarafından gerçekleştirilen değişimler özellikle sunulan mesajların ve içeriklerin nasıl iletileceği üzerinde yoğunlaşmıştır. İşletmelerin müşterilerine ulaşmada çevrim içi ortamlarda kullanacağ 1 araçlardan biri olarak e-posta pazarlaması son 25 yılın en hızlı büyüyen iletişim teknolojisi olarak görülmektedir (O’Connor, 2008). 1995 yılında e-posta kullanıcı sayısının 16 milyon olduğu ve Ocak 2020 itibariyle 4,5 milyara ulaştığ görülmektedir (Internet World Stats, 2020). 4,5 milyar kullanıcı tarafından gerçekleştirilen günlük e-posta trafiğinin 2019 yılı itibariyle 293 milyar olması (Radicati, 2019), en hızlı büyüyen iletişim teknolojisi olmasının yanı sıra yüksek trafiğe sahip bir araç olduğunu göstermektedir. Trafiğgin bu denli yüksek olması aynı zamanda gün içerisindeki aktif kullanımın ve geniş bir ağ üzerindeki yayılımını göstermektedir. E-posta aracılığıyla gerçekleştirilen pazarlama aktivitesi ise "e-posta pazarlaması" olarak isimlendirilmekte ve elektronik ortamdaki pazarlama araçlarından biri olarak ele alınmaktadır (Chittenden \& Rettie, 2003). 
E-posta pazarlaması, pazarlama iletişiminde firmaların müşterileriyle daha yakın ilişkiler kurmalarına olanak sağlayan bir araçtır (Chaffey vd., 2003; McCloskey, 2006). DuFrene vd., (2005) e-postanın birçok işletmenin; yeni tüketicilere ulaşma, satışları arttırma, var olan iletişimi sürdürme ve yeni müşteriler ile ilişkiler kurma gibi pazarlama stratejilerinde anahtar rol oynadığını belirtmektedir. Müşteriler tarafindan da e-postaların, ihtiyaçları olan ürünleri bulmalarında oldukça etkili olduğu belirtilmektedir (Gratton, 2003). E-postanın yayılarak daha geniş kitlelere ulaşması ile önemi daha da artarak geleneksel pazarlama metotlarına göre daha avantajlı ve pratik bir araç haline gelmiştir. E-posta pazarlamasına ekonomik açıdan bakıldığında ise hızlı ve düşük maliyetli olarak, hedeflenen kitleye doğrudan erişim sağlaması aracın en büyük avantajı olarak görülmektedir (Kinnard, 2002). Pratikliği ise zaman tasarrufu olarak öne çıkmakla birlikte, yüz bin veya beşyüz bin e-postanın zaman maliyetinin aynı olmasıdır (Krishnamurthy, 2001). Sahip olduğu bir diğer avantaj ise küçük ve orta ölçekli işletmelerde tanıtımlar, indirimler ve kuponlar gibi teşvik edici iletişimin gerçekleşmesini kolay ve etkili bir şekilde sağlamasıdır (Moustakas vd., 2006). Avantajları ve pratikliğinin yanı sıra, e-postaların küresel bir erişime sahip olması ile birlikte anlık ve ölçülebilir özelliklere sahip olması e-postayı çekici bir pazarlama aracı yapmaktadır (Nettleton, 2005).

E-posta birçok farklı sektörde pazarlama aracı olarak kullanılarak, pazarlama stratejilerinin gerçekleştirilmesinde aktif rol oynamaktadır. Uygulamaciların yanı sira literatürde de akademisyenler tarafindan e-posta pazarlamasının kullanıldığı farklı sektörler incelenmiştir. Farklı sektörler literatürde; otelcilik (O’Connor, 2008; Yang vd., 2018), bankacılık sektörü (Nath \& Gupta, 2013), yayımcıllk (Goff, 2011), perakendecilik (Heiens \& Narayanaswamy, 2016) ve emlakçılık (Acharya vd., 2010) olarak görülmektedir. Acharya vd., (2010) tarafından gerçekleştirilen çalışmada emlakçıların performansında e-posta pazarlamasının etkisi incelenmiştir. Acente performansının yeni teknolojilere yönelik algısının ve tutumunun, e-posta pazarlama aracının kullanımında etkili olduğu ve teknoloji kullanımının da ekonomik performans üzerinde etkili olduğu elde edilmiştir. Literatür ile paralellik gösteren sonuçlar e-posta pazarlamasının kullanılmasının işletmelere faydalar sunduğunu teyit etmektedir. Birçok sektörde e-posta pazarlamasının etkin rol almasının sebepleri arasında; kolay kullanılabilmesi, yüksek erişim sahipliği, düşük maliyetli oluşu, hızlı iletişim kurabilmesi ve doğrudan bir etkiye sahip olması gibi faydaları bulunmaktadır.

E-posta pazarlaması literatürü incelendiğinde hem ampirik hem de kavramsal çalışmalara ulaşılmıştır. Literatürde yer alan kavramsal çalışmalar (Tablo 1); tüketicilerin farklı kanallara dair atfettikleri özellikleri ve bu özelliklerin pazarlama etkinliklerinin edinimindeki davranışlarını e-posta pazarlaması üzerinden teoriye dayandırılması (Jain \& Reed, 2013), B2B pazarlamada verimli kullanımı (Dawe, 2015), tüketici güçlendirme için neden, ne zaman ve nasıl kullanılabileceği (Hartemo, 2016), pazarlamacılar için en iyi uygulama seçeneklerini özetlenmesi (Stevens, 2004), yasallık ve mevzuata dair güncellemeleri (Gaskill \& Hackett, 
2001), yasalara uygun şekilde gerçekleştirilmesini (Malcolm, 2004), istenmeyen ticari e-posta sürecine yönelik kavramsal bir bakış sunulması (Moustakas vd., 2006), e-posta pazarlamasında videoların kullanılmasına yönelik potansiyeli ve nasıl gerçekleştirileceğini (Anderson, 2003), küçük ve orta ölçekli B2B işletmelerin araştırılması (Liu, 2012), ticari e-posta mesajlarının gönderimi ve satış gücüne etkileri (Clarke vd., 2005), entegre değer yaratma süreci (Kucuk, 2011), gelenekselden yeni akıma geçişte araç olarak e-posta pazarlamasının kullanımı (Goff, 2011), online reklamcılıkta bir araç olan e-posta pazarlamasının etkili kullanım metodları (Sankar, 2019), stratejik yönetimdeki etkili internet pazarlaması araçlarının seçimi (Lagodiienko vd., 2019), sürdürülebilir e-posta pazarlama altyapıları (Pavlov vd., 2008), eğilimleri ve kullanım türlerine dair uygulamacıların etkinliklerine (Jain \& Garg, 2014) yöneliktir.

Tablo 1: E-Posta Pazarlaması Literatüründeki Kavramsal Çalışmalar ve Konular1

\begin{tabular}{|c|c|}
\hline Odaklanılan Konu & Kaynak \\
\hline Farklı platformlara ait tüketici dinamikleri ve özelliklerinin belirlenmesi & Jain \& Reed, 2013 \\
\hline B2B pazarlamada verimli kullanımı & Dawe, 2015 \\
\hline Tüketici Güçlendirme için neden, ne zaman ve nasıl kullanılabileceği & Hartemo, 2016 \\
\hline Pazarlamacılar için en iyi uygulama seçeneklerini özetlenmesi & Stevens, 2004 \\
\hline Yasallık ve mevzuata dair güncellemeleri & Gaskill \& Hackett, 2001 \\
\hline Yasalara uygun şekilde gerçekleştirilmesini & Malcolm, 2004 \\
\hline İstenmeyen ticari e-posta sürecine yönelik kavramsal bir bakış sunulması & Moustakas vd., 2006 \\
\hline $\begin{array}{l}\text { E-posta pazarlamasında videoların kullanılmasına yönelik potansiyeli ve nasıl } \\
\text { gerçekleştirileceğine dair kavramsal bir çerçeve oluşturulması }\end{array}$ & Anderson, 2003 \\
\hline Küçük ve orta ölçekli B2B işletmelerin araştırılması & Liu, 2012 \\
\hline Ticari e-posta mesajlarının gönderimi ve satış gücüne etkileri & Clarke vd., 2005 \\
\hline Entegre değer yaratma süreci & Kucuk, 2011 \\
\hline Gelenekselden yeni akıma geçişte araç olarak e-posta pazarlamasının kullanımı & Goff, 2011 \\
\hline $\begin{array}{l}\text { Çevrimiçi reklamcılıkta bir araç olan e-posta pazarlamasının etkili kullanım } \\
\text { metodları }\end{array}$ & Sankar, 2019 \\
\hline Stratejik yönetimdeki etkili internet pazarlaması araçlarının seçimi & Lagodiienko vd., 2019 \\
\hline Sürdürülebilir e-posta pazarlama altyapıları & Pavlov vd., 2008 \\
\hline Eğilimleri ve kullanım türlerine dair uygulamacıların etkinliklerine & Jain \& Garg, 2014 \\
\hline
\end{tabular}

Yazında yer alan ampirik çalışmalara bakıldığında ise nicel yöntem kullanılan çalışmaların baskınlığı görülmektedir. Literatürde yer alan nitel yöntemli olan tek çalışma Utkarsh \& Gupta (2018) tarafından gerçekleştirilmiştir. Nitel içerik 
analizi yapılarak gerçekleştirilen çalışma, tanıtım e-postalarındaki reklam içeriğinin pazarlamaya dair sunduğu öngörülerin analiz edilmesine odaklanmıştır. 698 adet tanıtım e-postası incelenen çalışmada e-posta pazarlamasının etkinliğinin ölçümü bu araçla gerçekleştirilmiştir. Sonucunda ise literatüre, içeriğinde yüksek seviyede bilgi sunan, yalnızca metinden oluşmayan ve duygusal bağ kurabilen e-posta içeriklerinin daha etkili olduğuna ulaşılarak, doğrudan uygulamaya yönelik sonuçlar ortaya konulmuştur.

Karma yöntemli ve işletme odaklı gerçekleştirilen çalışma ise Watjatrakul \& Drennan (2005) tarafından gerçekleştirilmiştir. E-postada odaklanılan alan, tasarım, içeriğin oluşturulması, test edilmesi, dağıtımı, izlenmesi, raporlanması ve analiz edilmesi gibi faaliyetlerden oluşan yerleşik yedi işlev sınıflandırması kullanılmıştır. İşlevlerin test edilmesinde, üç farklı analiz düzeyi kullanılarak, iki işlevin değerini ve belirsizliğini izlemek için vaka çalışmalarından yararlanılmıştır. Araştırmanın sonucu, işlevlerin yönetiminde kullanılan becerilerin ve örtük bilginin karar verme sürecinde önemli olarak, belirsizliği aştığını göstermektedir. Bu durum ise incelenen yedi işlevin e-posta pazarlaması için önemini ortaya koymaktadır.

Pazarlama iletişimlerinde birden fazla platformun aynı anda kullanılmasına yönelik Hamilton vd., (2016) tarafından gerçekleştirilen çalışma tüketici odağına sahiptir. Çalışmada, farklı platformlardaki marka-tüketici etkileşimleri incelenerek, tüketicilerin hangi platformlardan marka ile iletişim kuracağına dair motivasyonları ele alınmıştır. Karma yöntem ile gerçekleştirilen çalışmanın sonucunda promosyon veya teşvik talebinde olan tüketicilerin çoklu platformlarda aktif olduğu görülmüsstür. E-postalarda, yeni ürün tanıtımları, mağaza açılışları gibi içeriklerin kullanılarak platformlar arasında bağ oluşturulabileceği belirtilmiştir. Tüketiciler ile iletişimlerde eğlenceli, zamana duyarlı içeriklerin iletilmesinin ve ilgili içeriklerin önemi aktarılmıştır. Odaklanılan platformların işletme ve sektör özelinde farklılıklar taşıyarak etkili olduğu görülmektedir.

Literatür incelemelerinden de görüldüğ̈̈ üzere, e-posta pazarlaması çalışmaları tek bir sektör, yöntem veya analiz düzeyi üzerinde gerçekleşmeyerek farklı şekillerde ele alınmıştır. Gerçekleştirilen çalışma ile literatürde yer alan eposta pazarlaması çalışmalarına dair genel bir öngörü sağlanmıştır.

\section{ARAŞTIRMA METODOLOJISİ}

Şematik yazın taraması olarak tasarlanan bu çalışma e-posta pazarlaması alanında var olan literatürü haritalandırma ve sınıflandırma amacıyla gerçekleştirilmiştir. Literatürü haritalandırma ve sinıflandırma kriterleri Grant \& Booth (2009) ve Gough ve arkadaşları (2006) tarafından önerilen süreç izlenerek gerçekleştirilmiştir. İlgili süreçte arama ve tarama yoluyla ilgili çalışmaların bulunması, araştırmanın yönlendirilmesi için anahtar kelimelerin kullanılması, literatürün sayısal değerlerinin aktarılması, araştırma desenlerinin sunulması önerilmektedir. Gelecekte yapılacak olan çalışmalara yol gösterici olması, var olan çalışmaların tanımlanarak bağlamsallaştııılması ve literatürdeki boşlukların 
sunulması şematik yazın taramasının odağıdır (Grant \& Booth, 2009). İlgili odak çerçevesinde çalışmanın arama süreci 4 basamakta gerçekleştirilmiştir (Görsel 1). İlk aşamada e-posta pazarlaması literatürünü taramak adına elektronik veri tabanları belirlenmiştir. İkinci aşamada anahtar kelimelerin seçimi ile elektronik veri tabanlarında tarama sürecine başlanmıştır. Üçüncü aşamada tarama sonucunda ulaşılan çalışmalardan yalnızca hakemli dergilerde yayınlanmış olan makaleler kapsam dahiline alınmıştır. Pazarlama alanına geniş bir bakış sağlanması adına herhangi bir dergi kısıtı uygulanmamıştır. Tezler, bildiriler ve kitaplar ise kapsama dahil edilmemiştir. Dergilerin barındırdıkları makaleler ile en yüksek araştırma düzeyini temsil etmesi (Nord \& Nord, 1995) yalnızca makalelerin incelenmesini nedenselleştirmiştir. Dördüncü aşamada makalelerin seçimi anahtar kelimelerin makalenin isminde, özetinde veya anahtar kelimelerinde yer almasına göre gerçekleştirilmiştir. Beşinci aşamada arama sonuçları yalnızca pazarlama alanında olanlar, 1950-2019 yılları arasında yayınlananlar ve yazım dili İngilizce olanlarla sınırlandırılmıştır. Altıncı aşamada sınırlamalar sonucunda ulaşılan makaleler incelenerek çalışma katkı alanlarına göre filtrelenmiştir. Ardından çalışmalar Grant $\&$ Booth (2009) ve Gough ve arkadaşları (2006) tarafindan sunulan öneriler dikkate alınarak Littell ve arkadaşlarının (2008) kullandığı yol izlenerek yöntemlerine, veri toplama araçlarına, analiz birimlerine, yayınlandıkları dergilere ve yer aldıkları elektronik veri tabanlarına göre sınıflandırılmış ve raporlanmıştır. 
Cetin, C., Tiltay, M. A.

Görsel 1: Arama Aşamaları

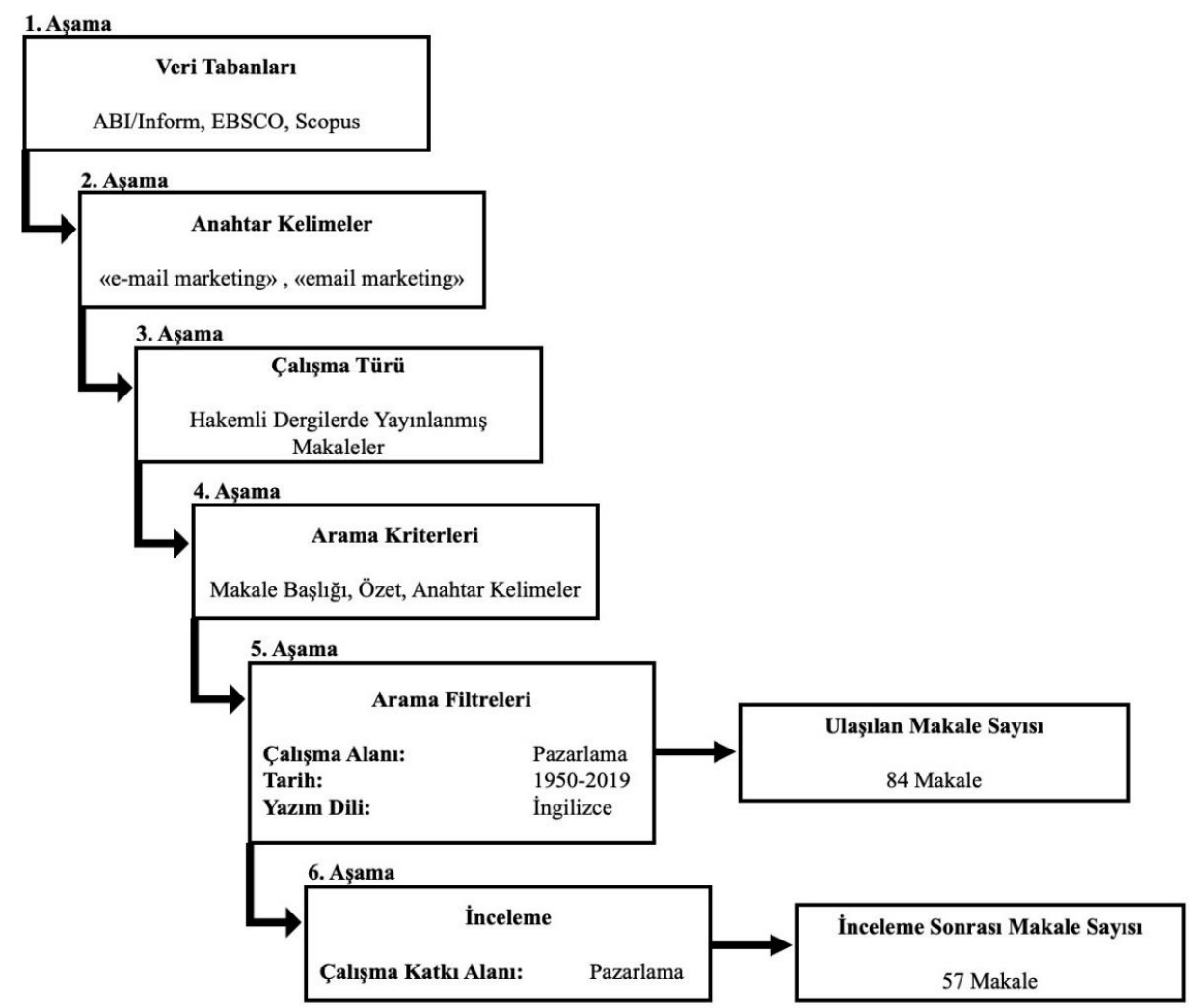

\section{Veri Tabanları}

Literatür taraması çalışması gerçekleştirilirken birden fazla veri tabanının incelenerek, geniş bir çerçeve yaratılması gerekmektedir (Green vd., 2006). İncelenmiş olan elektronik veri tabanlarının seçiminde Schibrowsky vd., (2007) incelenecek elektronik veri tabanlarının seçiminde iki karar kriterinin göz önüne alınması gerektiğini belirtmektedir. İlk kriter sahip olduğu dergi kapsamının geniş olmas1 ve ikinci kriter de uzun bir zaman diliminin incelenebilmesidir. Kriterler ve pazarlama literatüründe gerçekleştirilmiş diğer çalışmaların (Alalwan vd., 2017; Knight, 1999; Tafesse \& Skallerud, 2017) ele aldığı elektronik veri tabanları dikkate alınarak gerçekleştirilen seçim ile ABI/Inform, EBSCO (Business Source Premier), Scopus elektronik veri tabanlarından yararlanılmıştır. Yararlanılan veri tabanları literatürde ana veri tabanları olarak görülmektedir (Alalwan vd., 2017). ABI/INFORM veri tabanı ise önde gelen bir elektronik veri tabanı olarak görülmektedir (Knight, 1999). Önde gelen veri tabanlarının kullanılmasının sebebi olabildiğince geniş bir bakış açısı kazanmak olarak belirtilebilir. Literatürde yer alan diğer çalışmaların araştırma yöntemleri de incelenerek amaçlanan geniş bakış 
açısının kazanılmasında ana veri tabanlarının kullanımının fayda sağlayacağı düşünülmüştür.

\section{Dergi Dizini}

E-posta pazarlaması araştırmalarını içeren dergilerde yayınlanmış olan çalışmalar incelenerek, pazarlama odaklı yayınları içeren dergilerin seçilmesi haricinde bir kısıtlamaya gidilmemiştir. Kısıtlama gerçekleştirilmemesinin sebebi ise "e-posta pazarlaması" üzerine bir literatür taraması çalışması bulunmaması ve bu çalışmanın alanı ele alan ilk çalışma olacak olmasıdır. Dergi alanında bir kısıtlama gerçekleştirilmese dahi taramada yalnızca hakemli akademik dergiler incelenmiştir. Çalışmada yalnızca İngilizce dilinde yayın yapan dergiler ele alınmıştır. Tarama sonucunda ulaşılan dergiler ise şu şekildedir: "Asia Pacific Journal of Marketing and Logistics, Asian Journal of Business Research, Baltic Journal of Management, Contemporary Logistics, Cornell Hospitality Quarterly, Cornell Hotel and Restaurant Administration Quarterly, Electron Markets, Industrial Marketing Management, Int. J. Electronic Customer Relationship Management, Int. J. Sport Management and Marketing, Interactive Marketing, International Journal of Applied Business and Economic Research, International Journal of Electronic Commerce, International Journal of Electronic Marketing and Retailing, International Journal of Enterprise Information Systems, International Journal of Recent Technology and Engineering, International Journal on Customer Relations, Internet Research, Journal of Business \& Economic Statistics, Journal of Business Economics and Management, Journal of Business Research, Journal of Consumer Marketing, Journal of Database Marketing, Journal of Direct, Data and Digital Marketing Practice, Journal of Electronic Commerce in Organizations, Journal of Global Information Management, Journal of Marketing Channels, Journal of Marketing Communications, Journal of Marketing Management, Journal of Marketing Research, Journal of Personal Selling \& Sales Management, Journal of Product \& Brand Management, Journal of Promotion Management, Journal of Real Estate Literature, Journal of Research in Interactive Marketing, Journal of Targeting, Measurement and Analysis for Marketing, Journal of Vacation Marketing, Management Science, Managerial and Decision Economics, MarketTržište, Marketing Science, Economic Sciences Series, Publishing Research Quarterly, The Psychological Record".

\section{Tarama İşlemi}

Elektronik veri tabanlarındaki taramaların gerçekleştirilmesinde makalelere erişim için anahtar kelimeler kullanılmıştır. Ulaşılmak istenen makalelere erişimde anahtar kelimeler kullanılması ve araştırma konusuyla doğrudan ilişkili olması gerekmektedir (Synder, 2019). İlgili anahtar kelimeler "e-mail marketing" ve "email marketing" olarak seçilmiştir. Bu doğrultuda anahtar kelime aracılığıyla veri tabanlarında; başl1k, özet ve anahtar kelimeler için tarama gerçekleştirilmiştir. Literatürde yer alan birçok farklı alanda e-posta pazarlaması çalışması bulunsa dahi başlığında, özetinde ve anahtar kelimelerinde istenilen kritere sahip olmayan 
çalışmalar araştırmaya dahil edilmemiştir. Kriterler uygulandıktan sonra ulaşılan makalelerin çalışma katkı alanlarının tespiti adına inceleme gerçekleştirilmiştir. İstenilen kriterleri (başlikta, özette, anahtar kelimesinde arama terimlerinin bulunmasi) sağlamasına rağmen:

- Doğrudan e-posta pazarlaması ile ilgili olmayan çalışmalar,

- Pazarlama alanına katkıda bulunmayan çalışmalar,

- Bildiriler, yüksek lisans ve doktora tezleri, ders kitapları, akademik dergilerde yayınlanmamış olan makaleler,

literatür taramasına dahil edilmemiştir.

\section{BULGULAR}

Bulgular çalışmaların miktarlarına, odaklandığı konularına ve Littell vd., (2008) önerileri doğrultusunda yöntemlerine, veri toplama araçlarına, analiz birimlerine, yayınlandıkları dergilere ve yer aldıkları elektronik veri tabanlarına göre tasnif edilmiştir.

\section{Yayınlanan E-posta Pazarlaması Araştırması Miktarı}

Tarama kapsamında belirlenen 1950-2019 yılları arasında yayınlanmış toplam 84 adet e-posta pazarlaması çalışmasına ulaşılmıştır. Anahtar kelime, başlık, özet odaklı taramalar ve incelemeler sonrasında erişilen çalışma sayısı 57'dir. Elektronik veri tabanlarında 1950'den 2001 yılına kadar bu konu üzerine gerçekleştirilmiş bir çalışma bulunmamaktadır. Grafik 1 incelendiğinde 2007 ve 2009 yıllarında e-posta pazarlaması üzerine çalışma gerçekleştirilmediği, 2016 yılının ise 11 adet ile en yüksek sayıda çalışmanın gerçekleştiği yıl olarak görülmektedir.

Grafik 1: Y1llara göre E-Posta Pazarlaması Üzerine Gerçekleştirilen Makale Sayıları

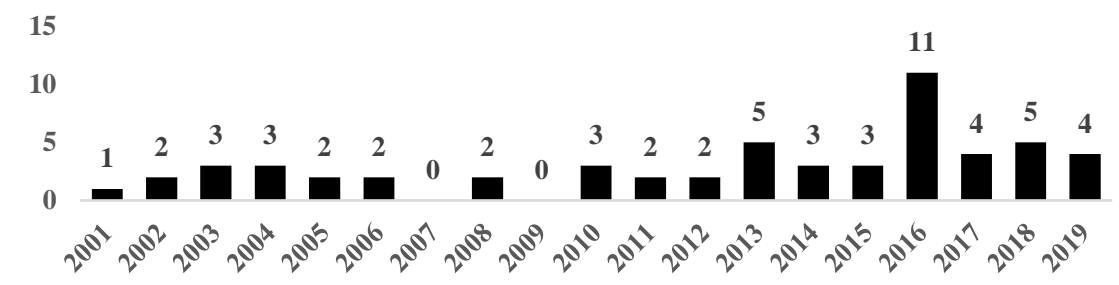

\section{E-posta Pazarlaması Çalışmalarının Yayınlandığı Dergiler}

E-posta pazarlaması çalışmalarının birçok farklı alanda gerçekleştiğine ulaşılmıştır. Arama filtreleri dahilinde taranan dergilerde çalışma alanının pazarlama olarak seçilmesi belirli alanın dışında kalan dergileri kapsam dışında bırakmıştır. Belirlenen sınırların dışında yer alan dergilerin de e-posta pazarlaması konusunda çalışmalar içerdiği bilinmektedir. E-posta pazarlamasını pazarlama alanında inceleyen çalışmalara yer veren 43 akademik ve hakemli dergi tespit edilmiştir 
(Tablo 2). Dergilerin 27'si Web of Science veri tabanında yer alırken (Tablo 3), geriye kalan 16 dergi ise Web of Science kapsamında değildir.

Tablo 2, e-posta pazarlaması alanındaki çalışmaların yayınlandığı akademik dergilere dair bir görünüm sunmaktadır. Journal of Direct, Data and Digital Marketing Practice, 7 e-posta pazarlaması çalışması ile toplam 57 makalenin $\% 12$ 'sini oluşturarak en fazla makale içeren akademik dergidir. Ardından içerdiği 4 adet çalışma ile Interactive Marketing kapsam dahiline alınan makalelerin \%7'sini oluşturmaktadır. İncelenen kapsamda makale sayısı bazında baskın olan bir akademik dergi bulunmamaktadır 
Cetin, C., Tiltay, M. A. DEÜ SBE Dergisi,

Cilt: 23, Sayı: 4

Tablo 2: E-Posta Pazarlaması Çalışmalarının Yayınlandığı Akademik Dergiler ve Dergi Başına Yayın Sayısı 
E-Posta Pazarlaması Alanında ...

DEU Journal of GSSS,

Vol: 23, Issue: 4

\begin{tabular}{|c|c|c|c|}
\hline 青 & 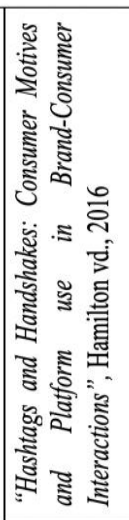 & 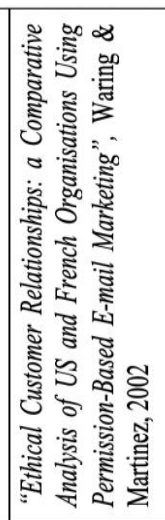 & 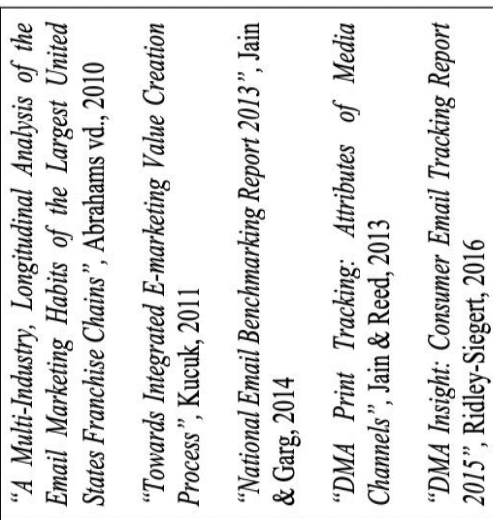 \\
\hline 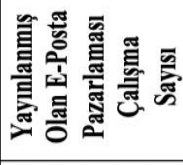 & - & - & r \\
\hline 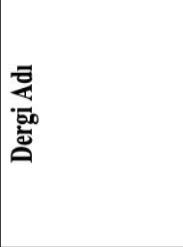 & 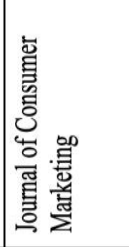 & 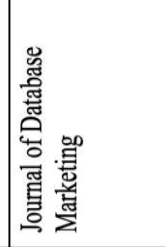 & 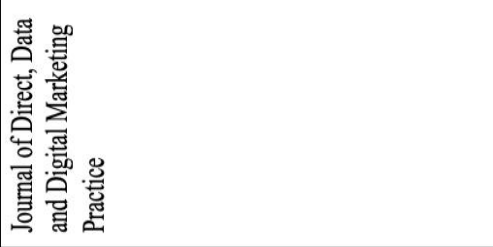 \\
\hline 善 & 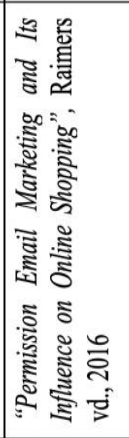 & 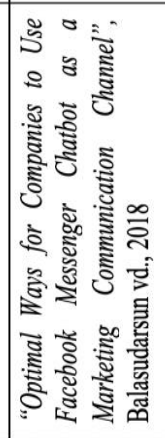 & 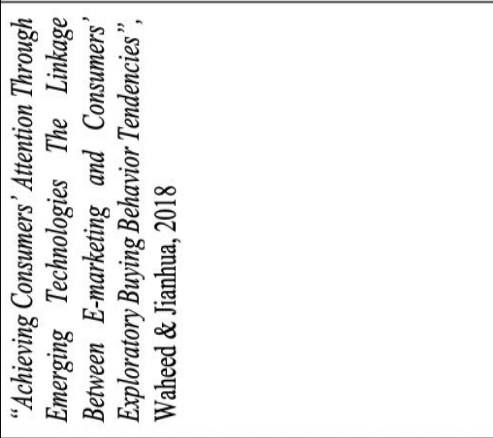 \\
\hline 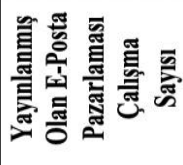 & - & - & - \\
\hline 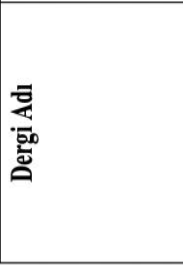 & 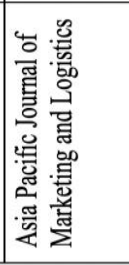 & 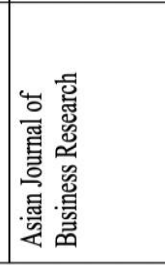 & 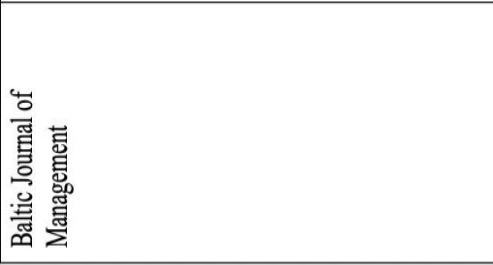 \\
\hline
\end{tabular}


Cetin, C., Tiltay, M. A.

DEÜ SBE Dergisi,

Cilt: 23, Sayı: 4

\begin{tabular}{|c|c|c|c|c|c|c|}
\hline 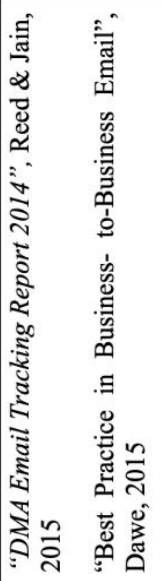 & 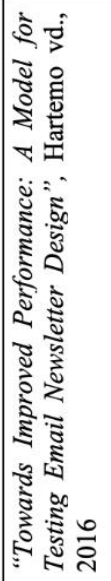 & 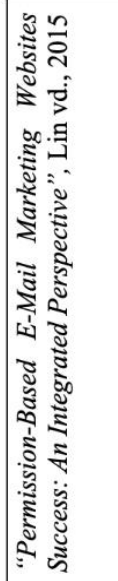 & 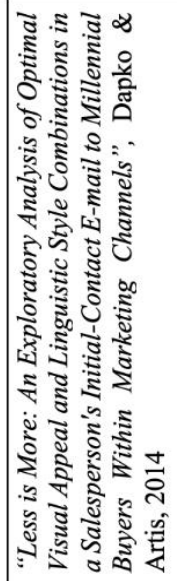 & 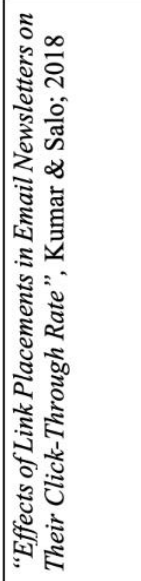 & 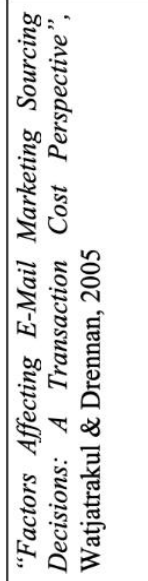 & 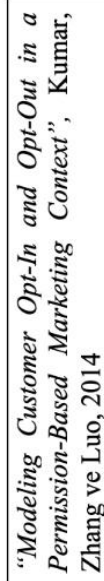 \\
\hline & - & - & - & - & - & $\sim$ \\
\hline & 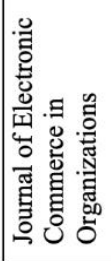 & 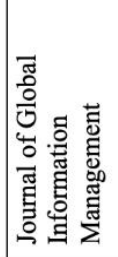 & 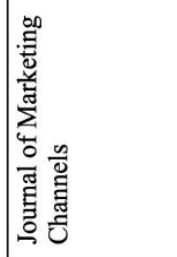 & 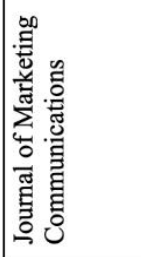 & 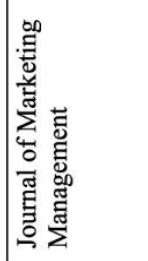 & 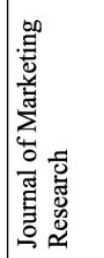 \\
\hline & 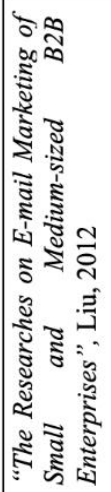 & 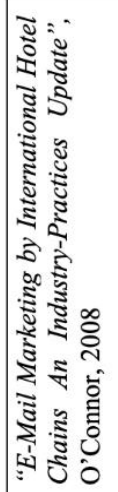 & 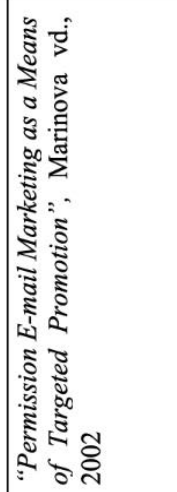 & 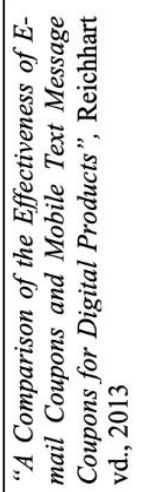 & 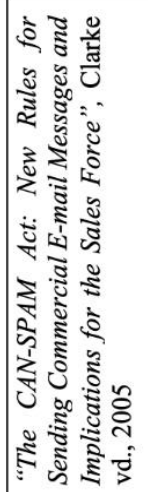 & 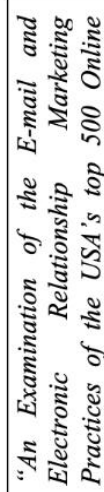 \\
\hline & - & - & - & - & - & - \\
\hline & 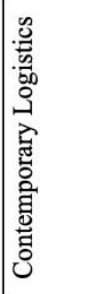 & 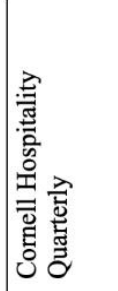 & 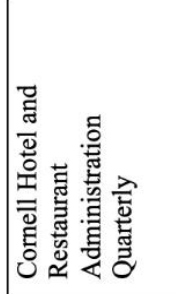 & 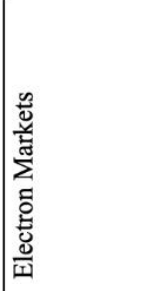 & 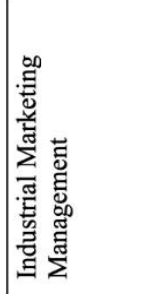 & 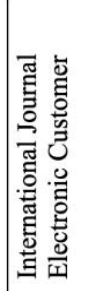 \\
\hline
\end{tabular}


E-Posta Pazarlaması Alanında ...

DEU Journal of GSSS,

Vol: 23, Issue: 4

\begin{tabular}{|c|c|c|c|c|}
\hline 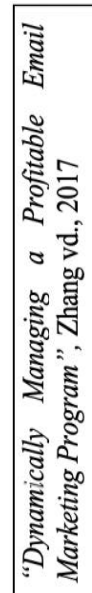 & 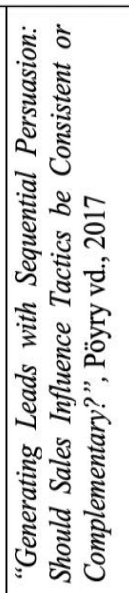 & 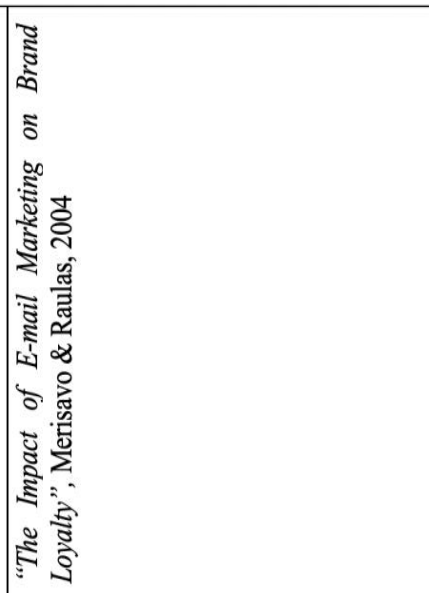 & 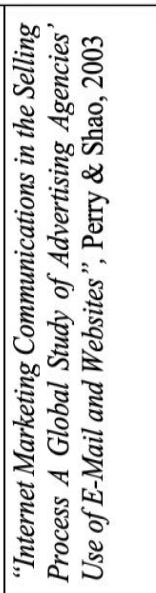 & 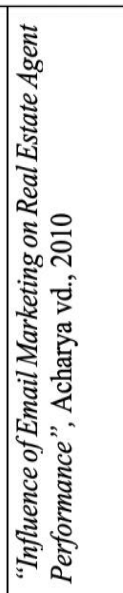 \\
\hline & - & $\rightarrow$ & - & - \\
\hline & 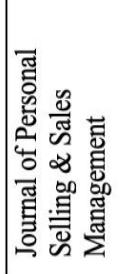 & 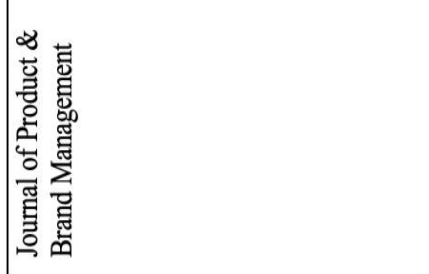 & 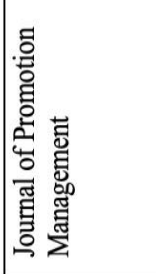 & 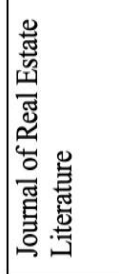 \\
\hline 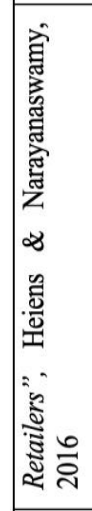 & 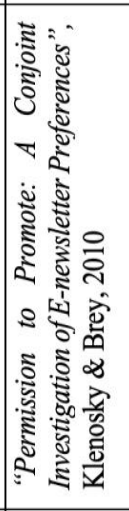 & 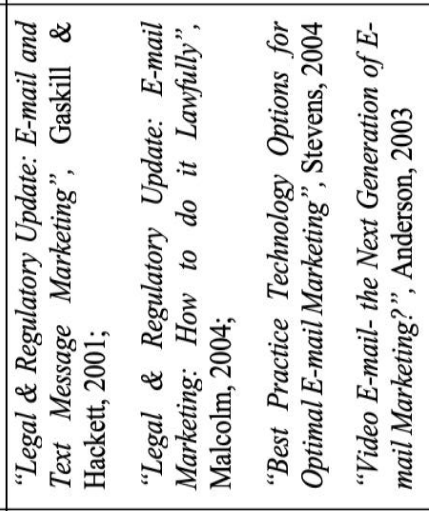 & 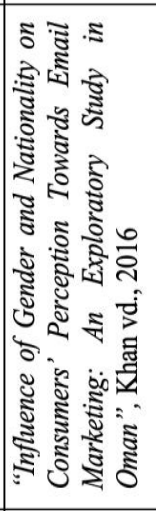 & 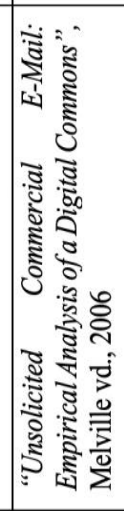 \\
\hline & - & t & - & - \\
\hline 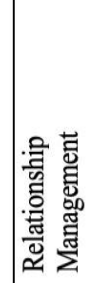 & 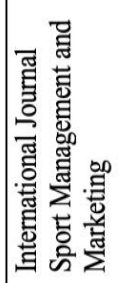 & 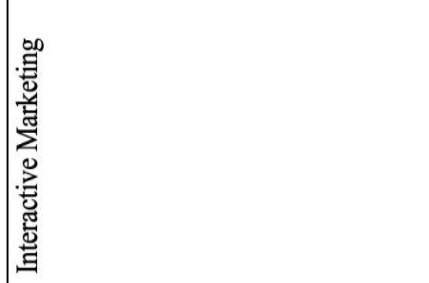 & 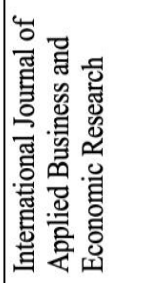 & 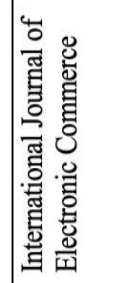 \\
\hline
\end{tabular}


Cetin, C., Tiltay, M. A.

DEÜ SBE Dergisi,

Cilt: 23, Sayı: 4

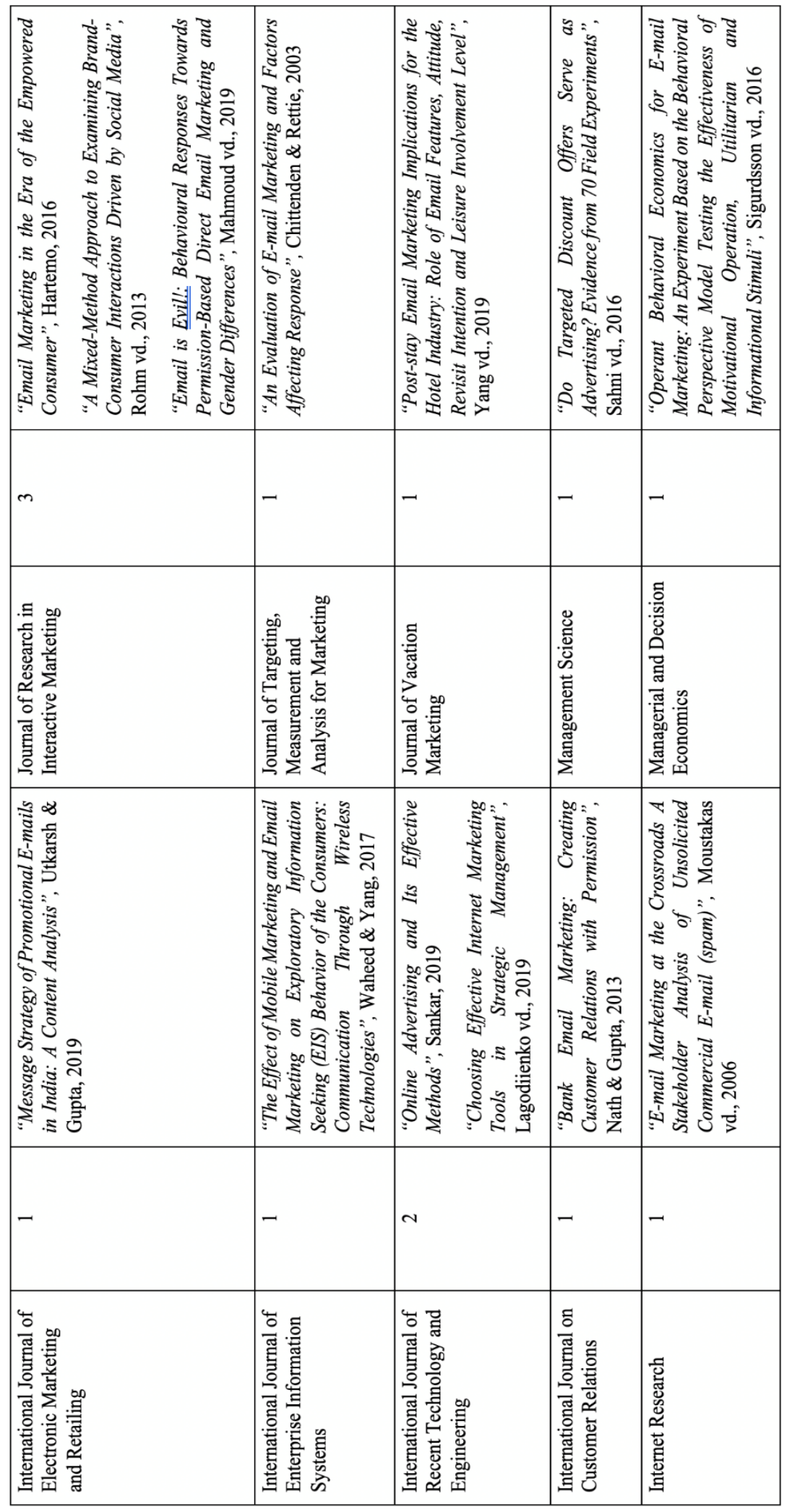


E-Posta Pazarlamasi Alaninda...

DEU Journal of GSSS,

Vol: 23, Issue: 4

\begin{tabular}{|c|c|c|c|}
\hline 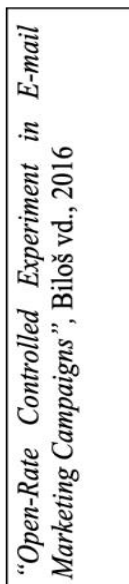 & 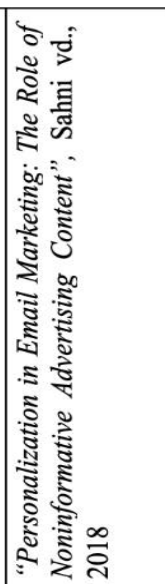 & 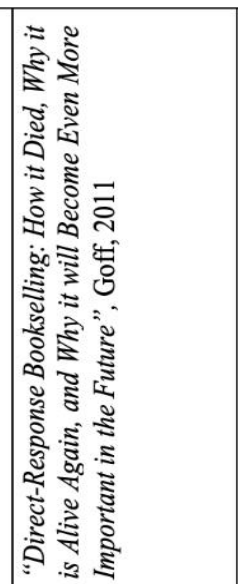 & 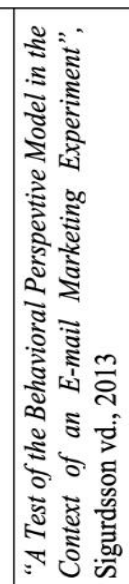 \\
\hline- & - & - & - \\
\hline 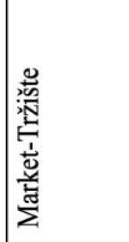 & 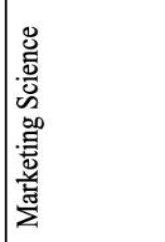 & 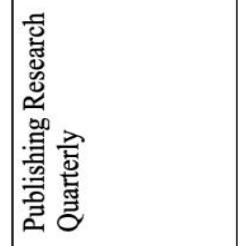 & 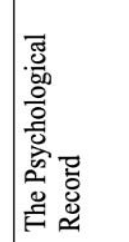 \\
\hline 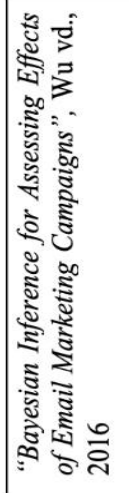 & 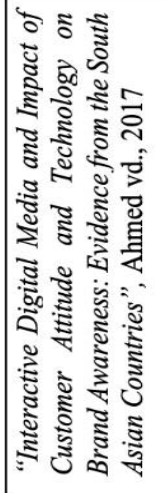 & 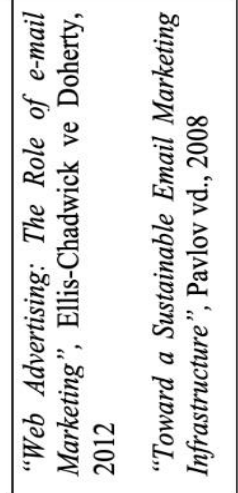 & \\
\hline- & - & $\sim$ & \\
\hline 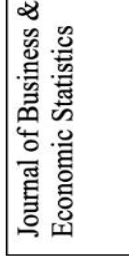 & 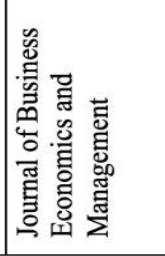 & 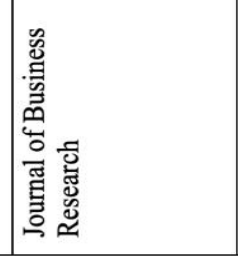 & \\
\hline
\end{tabular}


Tablo 3: Web of Science'da Taranan Akademik Dergiler Bazında Yayınlanmış Çalışmalar

\begin{tabular}{|c|c|c|}
\hline $\begin{array}{l}\text { Yayınlanmış } \\
\text { Çalışma } \\
\text { Sayıları }\end{array}$ & Web of Science Dergileri & Kaynak Dizini \\
\hline 1 & Asia Pacific Journal of Marketing and Logistics & Raimers vd., 2016 \\
\hline 1 & Baltic Journal of Management & Waheed \& Jianhua, 2018 \\
\hline 1 & Cornell Hospitality Quarterly & O'Connor, 2008 \\
\hline 1 & Industrial Marketing Management & Clarke vd., 2005 \\
\hline 4 & Interactive Marketing & $\begin{array}{l}\text { Anderson, 2003; Gaskill \& Hackett, 2001; } \\
\text { Malcolm, 2004; Stevens, } 2004\end{array}$ \\
\hline 1 & International Journal of Electronic Commerce & Melville vd., 2006 \\
\hline 1 & $\begin{array}{l}\text { International Journal of Enterprise Information } \\
\text { Systems }\end{array}$ & Waheed \& Yang, 2017 \\
\hline 1 & Internet Research & Moustakas vd., 2006 \\
\hline 1 & Journal of Business \& Economic Statistics & Wu vd., 2016 \\
\hline 1 & $\begin{array}{l}\text { Journal of Business Economics and } \\
\text { Management }\end{array}$ & Ahmedi vd., 2016 \\
\hline 2 & Journal of Business Research & $\begin{array}{l}\text { Ellis-Chadwick \& Doherty, 2012; Pavlov vd., } \\
2008\end{array}$ \\
\hline 1 & Journal of Consumer Marketing & Hamilton vd., 2016 \\
\hline 1 & $\begin{array}{l}\text { Journal of Electronic Commerce in } \\
\text { Organizations }\end{array}$ & Hartemo vd., 2016 \\
\hline 1 & Journal of Global Information Management & Lin vd., 2015 \\
\hline 1 & Journal of Marketing Channels & Dapko \& Artis, 2014 \\
\hline 1 & Journal of Marketing Management & Watjatrakul \& Drennan, 2005 \\
\hline 2 & Journal of Marketing Research & Kumar vd., 2014; Zhang vd., 2017 \\
\hline 1 & $\begin{array}{l}\text { Journal of Personal Selling \& Sales } \\
\text { Management }\end{array}$ & Pöyry vd., 2017 \\
\hline 1 & Journal of Product \& Brand Management & Merisavo \& Raulas, 2004 \\
\hline 3 & Journal of Research in Interactive Marketing & $\begin{array}{l}\text { Hartemo, 2016; Rohm vd., 2013; Mahmoud vd., } \\
2019\end{array}$ \\
\hline 1 & Journal of Vacation Marketing & Yang vd., 2019 \\
\hline 1 & Management Science & Sahni vd., 2016 \\
\hline 1 & Managerial and Decision Economics & Sigurdsson vd., 2016 \\
\hline 1 & Market-Tržište & Biloš vd., 2016 \\
\hline 1 & Marketing Science & Sahni vd., 2018 \\
\hline 1 & Publishing Research Quarterly & Goff, 2011 \\
\hline 1 & The Psychological Record & Sigurdsson vd., 2013 \\
\hline
\end{tabular}


E-Posta Pazarlamasi Alanında...

DEU Journal of GSSS,

Vol: 23, Issue: 4

Grafik 1'den görülebildiği üzere, e-posta pazarlamas1 çalışmalarının yıl bazında doğrusal bir şekilde arttığ veya azaldığı söylenememektedir. Düzenli bir eğriye sahip değildir. Verilen grafiğe dair detaylı bir görünüm Tablo 4'te görülmektedir. Araştırmamızda ele alınan ilk tarih 1950 iken 2001 yılına kadar e-posta pazarlamasına dair bir çalışma gerçekleştirilmemiştir. İlk çalışma ise Gaskill \& Hackett (2001) tarafindan gerçekleştirilmiştir. Takip eden y1llarda çalışmalar görülmekle birlikte, 2007 ve 2009 yıllarında incelenen alanda çalışmaya rastlanılmamıştır. En fazla çalışma ise 11 adet ile 2016 yılında gerçekleşmiştir. 
Cetin, C., Tiltay, M. A. DEÜ SBE Dergisi,

Cilt: 23, Sayl: 4

Tablo 4: Y1llara Göre Akademik Dergiler Bazında Yayınlanan E-Posta Pazarlamas1

Çalışmaları

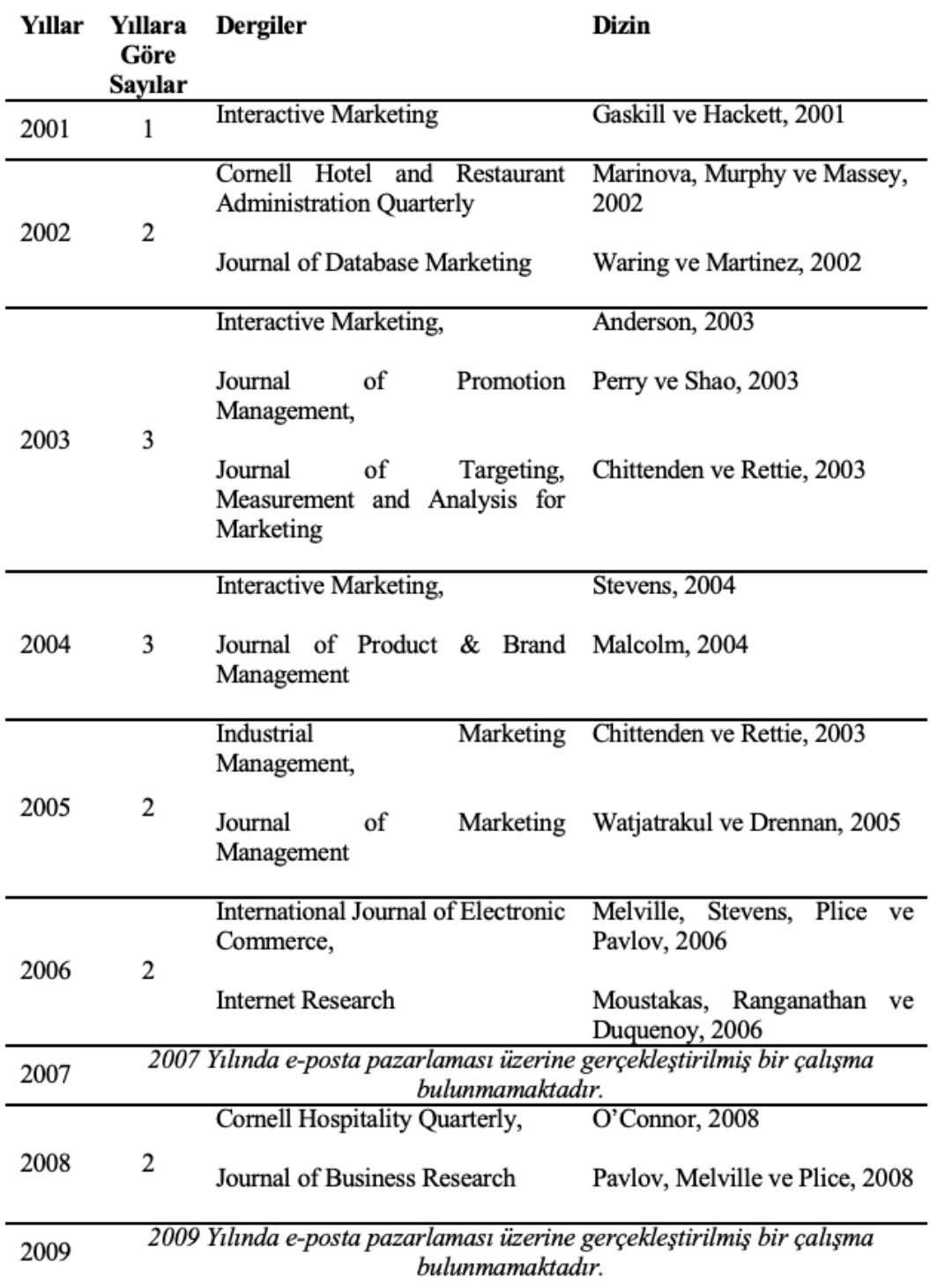




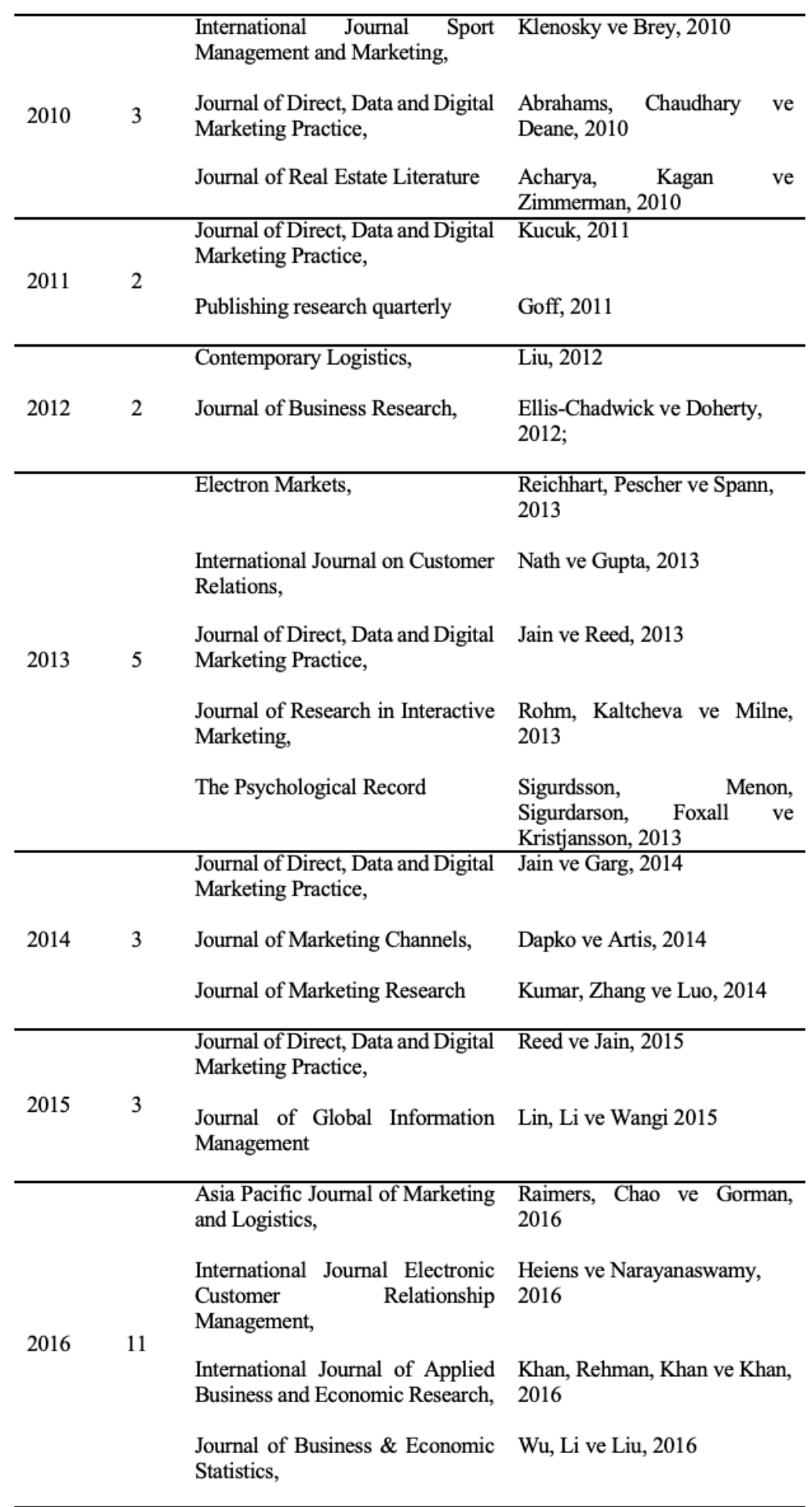


Cetin, C., Tiltay, M. A.

DEÜ SBE Dergisi,

Cilt: 23, Sayz: 4

\begin{tabular}{|c|c|c|c|}
\hline & & Journal of Consumer Marketing, & $\begin{array}{l}\text { Hamilton, Kaltcheva ve Rohm, } \\
2016\end{array}$ \\
\hline & & $\begin{array}{l}\text { Journal of Direct, Data and Digital } \\
\text { Marketing Practice, }\end{array}$ & Ridley-Siegert, 2016 \\
\hline & & $\begin{array}{l}\text { Journal of Electronic Commerce } \\
\text { in Organizations, }\end{array}$ & $\begin{array}{l}\text { Hartemo, Suomi ve Hakala, } \\
2016\end{array}$ \\
\hline & & $\begin{array}{l}\text { Journal of Research in Interactive } \\
\text { Marketing. }\end{array}$ & Hartemo, 2016 \\
\hline & & Management Science, & $\begin{array}{l}\text { Sahni, Zou ve Chintagunta, } \\
2016\end{array}$ \\
\hline & & $\begin{array}{l}\text { Managerial and Decision } \\
\text { Economics, }\end{array}$ & $\begin{array}{l}\text { Sigurdsson, Hinriksson ve } \\
\text { Menon, } 2016\end{array}$ \\
\hline & & Market-Tržište & Biloš, Turkalj ve Kelić, 2016 \\
\hline & & $\begin{array}{l}\text { International Journal of Enterprise } \\
\text { Information Systems, }\end{array}$ & Waheed ve Yang, 2017 \\
\hline & & $\begin{array}{l}\text { Journal of Business Economics } \\
\text { and Management, }\end{array}$ & $\begin{array}{l}\text { Ahmed, Vveinhardt } \\
\text { Streimikiene, } 2017\end{array}$ \\
\hline 2017 & 4 & Journal of Marketing Research, & $\begin{array}{l}\text { Zhang, Kumar ve Cosguner, } \\
2017\end{array}$ \\
\hline & & $\begin{array}{l}\text { Journal of Personal Selling \& } \\
\text { Sales Management }\end{array}$ & $\begin{array}{l}\text { Pöyry, Parvinen ve McFarland, } \\
2017\end{array}$ \\
\hline & & $\begin{array}{l}\text { Asian Journal of Business } \\
\text { Research, }\end{array}$ & $\begin{array}{l}\text { Balasudarsun, Sathish ve } \\
\text { Gowtham, } 2018\end{array}$ \\
\hline & & Baltic Journal of Management, & Waheed, Jianhua, 2018 \\
\hline 2018 & 5 & $\begin{array}{l}\text { Journal of } \\
\text { Communications, }\end{array}$ & Kumar ve Salo, 2018 \\
\hline & & Journal of Vacation Marketing, & $\begin{array}{l}\text { Yang, Min ve Garza-Baker, } \\
2019\end{array}$ \\
\hline & & Marketing Science & $\begin{array}{l}\text { Sahni, Wheeler ve Chintagunta, } \\
2018\end{array}$ \\
\hline & & $\begin{array}{l}\text { International Journal of Recent } \\
\text { Technology and Engineering, }\end{array}$ & $\begin{array}{l}\text { Lagodiienko, Karyy, Ohiienko, } \\
\text { Kalaman, Lorvi } \\
\text { Herasimchuk, } 2019\end{array}$ \\
\hline 2019 & 4 & $\begin{array}{l}\text { International Journal of Electronic } \\
\text { Marketing and Retailing, }\end{array}$ & Utkarsh ve Gupta, 2019 \\
\hline & & $\begin{array}{l}\text { Journal of Research in Interactive } \\
\text { Marketing }\end{array}$ & $\begin{array}{l}\text { Mahmoud, Grigoriou ve Hack- } \\
\text { Polay, } 2019\end{array}$ \\
\hline
\end{tabular}


E-Posta Pazarlamasi Alanında...

DEU Journal of GSSS,

Vol: 23, Issue: 4

*Her dergi karşı sırasında yer alan dizin ile eşleşmektedir.

E-Posta Pazarlaması Çalışmalarının İncelendiği Elektronik Veri Tabanları

Dergi kapsamlılığı ve incelenecek zamana uygunluk açısından seçilerek, akademik dergilere erişimde kullanılan elektronik veri tabanları kapsamındaki dağılım Tablo 5 'ten görülebilmektedir. En fazla çalışmaya 36 ile Scopus elektronik veri tabanından erişilirken, 18 çalışmaya ABI/INFORM aracılığıyla ve 3 çalışmaya ise EBSCO ile erişim sağlanmıştır. 
Cetin, C., Tiltay, M. A.

DEÜ SBE Dergisi,

Cilt: 23, Sayl: 4

Tablo 5: Veri Tabanları Bazında Akademik Dergiler ve Yer Alan E-Posta $\quad$ Pazarlaması Çalışmaları

\begin{tabular}{|c|c|c|c|c|c|c|c|}
\hline & $\begin{array}{c}\text { ABI/ } \\
\text { INFORM }\end{array}$ & EBSCO & SCOPUS & & $\begin{array}{c}\text { ABI/ } \\
\text { INFORM }\end{array}$ & $\overline{\text { EBSCO }}$ & SCOPUS \\
\hline \multicolumn{8}{|c|}{ Dergi İsimleri } \\
\hline $\begin{array}{l}\text { Asia Pacific } \\
\text { Journal of } \\
\text { Marketing } \\
\text { and } \\
\text { Logistics }\end{array}$ & 1 & & & $\begin{array}{l}\text { Journal of } \\
\text { Consumer } \\
\text { Marketing }\end{array}$ & & & 1 \\
\hline $\begin{array}{l}\text { Asian } \\
\text { Journal of } \\
\text { Business } \\
\text { Research }\end{array}$ & & & 1 & $\begin{array}{l}\text { Journal of } \\
\text { Database } \\
\text { Marketing }\end{array}$ & 1 & & \\
\hline $\begin{array}{l}\text { Baltic } \\
\text { Journal of } \\
\text { Managemen } \\
t\end{array}$ & & & 1 & $\begin{array}{l}\text { Journal of } \\
\text { Direct, Data } \\
\text { and Digital } \\
\text { Marketing } \\
\text { Practice } \\
\end{array}$ & 1 & & 6 \\
\hline $\begin{array}{l}\text { Contempora } \\
\text { ry Logistics }\end{array}$ & 1 & & & $\begin{array}{l}\text { Journal of } \\
\text { Electronic } \\
\text { Commerce in } \\
\text { Organizations }\end{array}$ & & & 1 \\
\hline $\begin{array}{l}\text { Cornell } \\
\text { Hospitality } \\
\text { Quarterly }\end{array}$ & & & 1 & $\begin{array}{l}\text { Journal of } \\
\text { Global } \\
\text { Information } \\
\text { Management }\end{array}$ & & & 1 \\
\hline $\begin{array}{l}\text { Cornell } \\
\text { Hotel and } \\
\text { Restaurant } \\
\text { Administrati } \\
\text { on Quarterly } \\
\end{array}$ & & & 1 & $\begin{array}{l}\text { Journal of } \\
\text { Marketing } \\
\text { Channels }\end{array}$ & & & 1 \\
\hline $\begin{array}{l}\text { Electron } \\
\text { Markets }\end{array}$ & & & 1 & $\begin{array}{l}\text { Journal of } \\
\text { Marketing } \\
\text { Communicati } \\
\text { ons }\end{array}$ & & & 1 \\
\hline $\begin{array}{l}\text { Industrial } \\
\text { Marketing } \\
\text { Managemen } \\
\mathrm{t}\end{array}$ & & & 1 & $\begin{array}{l}\text { Journal of } \\
\text { Marketing } \\
\text { Management }\end{array}$ & 1 & & \\
\hline $\begin{array}{l}\text { International } \\
\text { Journal } \\
\text { Electronic } \\
\text { Customer } \\
\text { Relationship } \\
\text { Managemen } \\
\mathrm{t} \\
\end{array}$ & & & 1 & $\begin{array}{l}\text { Journal of } \\
\text { Marketing } \\
\text { Research }\end{array}$ & 1 & & 1 \\
\hline $\begin{array}{l}\text { International } \\
\text { Journal } \\
\text { Sport } \\
\text { Managemen } \\
\text { t and } \\
\text { Marketing } \\
\end{array}$ & & & 1 & $\begin{array}{l}\text { Journal of } \\
\text { Personal } \\
\text { Selling \& } \\
\text { Sales } \\
\text { Management } \\
\end{array}$ & & & 1 \\
\hline
\end{tabular}


E-Posta Pazarlamasi Alanında...

DEU Journal of GSSS,

Vol: 23, Issue: 4

\begin{tabular}{|c|c|c|c|c|c|c|c|}
\hline $\begin{array}{l}\text { Interactive } \\
\text { Marketing }\end{array}$ & 4 & & & $\begin{array}{l}\text { Journal of } \\
\text { Product \& } \\
\text { Brand } \\
\text { Management }\end{array}$ & & & 1 \\
\hline $\begin{array}{l}\text { International } \\
\text { Journal of } \\
\text { Applied } \\
\text { Business } \\
\text { and } \\
\text { Economic } \\
\text { Research }\end{array}$ & & & 1 & $\begin{array}{l}\text { Journal of } \\
\text { Promotion } \\
\text { Management }\end{array}$ & & & 1 \\
\hline $\begin{array}{l}\text { International } \\
\text { Journal of } \\
\text { Electronic } \\
\text { Commerce }\end{array}$ & & & 1 & $\begin{array}{l}\text { Journal of } \\
\text { Real Estate } \\
\text { Literature }\end{array}$ & 1 & & \\
\hline $\begin{array}{l}\text { International } \\
\text { Journal of } \\
\text { Electronic } \\
\text { Marketing } \\
\text { and } \\
\text { Retailing }\end{array}$ & & & 1 & $\begin{array}{l}\text { Journal of } \\
\text { Research in } \\
\text { Interactive } \\
\text { Marketing }\end{array}$ & 1 & & 2 \\
\hline $\begin{array}{l}\text { International } \\
\text { Journal of } \\
\text { Enterprise } \\
\text { Information } \\
\text { Systems }\end{array}$ & 1 & & & $\begin{array}{l}\text { Journal of } \\
\text { Targeting, } \\
\text { Measurement } \\
\text { and Analysis } \\
\text { for Marketing }\end{array}$ & 1 & & \\
\hline $\begin{array}{l}\text { International } \\
\text { Journal of } \\
\text { Recent } \\
\text { Technology } \\
\text { and } \\
\text { Engineering }\end{array}$ & & & 2 & $\begin{array}{l}\text { Journal of } \\
\text { Vacation } \\
\text { Marketing }\end{array}$ & 1 & & \\
\hline $\begin{array}{l}\text { International } \\
\text { Journal on } \\
\text { Customer } \\
\text { Relations }\end{array}$ & 1 & & & $\begin{array}{l}\text { Management } \\
\text { Science }\end{array}$ & & & 1 \\
\hline $\begin{array}{l}\text { Internet } \\
\text { Research }\end{array}$ & & 1 & & $\begin{array}{l}\text { Managerial } \\
\text { and Decision } \\
\text { Economics }\end{array}$ & & & 1 \\
\hline $\begin{array}{l}\text { Journal of } \\
\text { Business \& } \\
\text { Economic } \\
\text { Statistics }\end{array}$ & & 1 & & $\begin{array}{l}\text { Market- } \\
\text { Tržište }\end{array}$ & & & 1 \\
\hline $\begin{array}{l}\text { Journal of } \\
\text { Business } \\
\text { Economics } \\
\text { and } \\
\text { Managemen } \\
t\end{array}$ & & & 1 & $\begin{array}{l}\text { Marketing } \\
\text { Science }\end{array}$ & 1 & & \\
\hline $\begin{array}{l}\text { Journal of } \\
\text { Business } \\
\text { Research }\end{array}$ & 1 & & 1 & $\begin{array}{l}\text { Publishing } \\
\text { Research } \\
\text { Quarterly }\end{array}$ & & & 1 \\
\hline & & & & $\begin{array}{l}\text { The } \\
\text { Psychological } \\
\text { Record }\end{array}$ & & 1 & \\
\hline $\begin{array}{l}\text { Dergilere } \\
\text { Göre } \\
\text { Toplam } \\
\text { Sayılar } \\
\end{array}$ & 18 & 3 & 36 & \multicolumn{4}{|c|}{ Toplam Makale Sayısı: 57} \\
\hline
\end{tabular}




\section{E-Posta Pazarlaması Çalışmalarının Odaklandığı Konular}

E-posta pazarlaması çalışmaları kapsamında (Tablo 6), 11 çalışma ile en fazla odaklanılan alan "tüketici davranışları"dır. 8'er adet çalışma ile "pazarlama stratejileri” ve "pazarlama iletişimi”" en çok yayın gerçekleştirilen diğer başlıklar olmuştur.

Çalışma kapsamında ele alınan makalelerin bir kısmının odağı pazarlama ile doğrudan olmasa dahi dolaylı yollarla ilişkilidir. E-posta pazarlaması odağında bu çalışmaların alana dair geniş bir görüş sağlayacağı düşünüldüğünden çalışmaya dahil edilmiştir. Bahsi geçen çalışmaların odakları ise şu şekildedir:

- Çevrim içi perakendecilik (Heiens \& Narayanaswamy, 2016)

- Davranıssal ekonomi (Sigurdsson vd., 2013)

- Davranışsal perspektif (Sigurdsson vd., 2013)

- Dinamik programlama (Zhang vd., 2017)

- Emlakçıllk (Acharya vd., 2010)

- Fiyat elastikiyeti (Reichhart vd., 2013)

- Karlilık(Zhang vd., 2017)

- Marka sadakati (Merisavo \& Raulas, 2004)

- Marka farkindalığ (Ahmed vd., 2017)

- Marka ilişkisi (Hamilton vd., 2016)

- Misafirperverlik yönetimi (Yang vd., 2018)

- Müşsteri tutumları (Yang vd., 2018)

- Müsteri siniflama (Yang vd., 2018)

- Otel endüstrisi (O'Connor, 2008)

- Satin alma (Wu vd., 2016)

- Satış yönetimi (Clarke vd., 2005)

- Sistem dinamikleri (Pavlov vd., 2008)

- Spamming (Pavlov vd., 2008)

- Stratejik yönetim (Lagodiienko vd., 2019)

- Veri gizliliği (O'Connor, 2008)

- Veri gizliliği düzenlemeleri (Malcolm, 2004)

- Veri tabanl pazarlama (Reed ve Jain, 2015; Stevens, 2004) 
E-Posta Pazarlaması Alanında ...

DEU Journal of GSSS,

Vol: 23, Issue: 4

Tablo 6: Odaklanılan Konulara Göre Akademik Dergilerde Yayınlanmış Olan E-Posta Pazarlaması Çalışmaları

\begin{tabular}{|c|c|c|c|}
\hline $\begin{array}{l}\text { Odaklanılan } \\
\text { Konular }\end{array}$ & $\begin{array}{l}\text { Konulara } \\
\text { Ait } \\
\text { Çalıșma } \\
\text { Sayları } \\
\end{array}$ & Dergiler & Dizin \\
\hline $\begin{array}{l}\text { Ağ } \\
\text { Pazarlaması }\end{array}$ & 1 & Contemporary Logistics & Liu, 2012 \\
\hline $\begin{array}{l}\text { B2B } \\
\text { Pazarlama }\end{array}$ & 1 & $\begin{array}{l}\text { Journal of Direct, Data and } \\
\text { Digital Marketing Practice }\end{array}$ & Dawe, 2015 \\
\hline $\begin{array}{l}\text { Çevrimiçi } \\
\text { Alışveriş }\end{array}$ & 1 & $\begin{array}{l}\text { Asia Pacific Journal of } \\
\text { Marketing and Logistics }\end{array}$ & $\begin{array}{l}\text { Reimers, Chao ve } \\
\text { Gorman, } 2016\end{array}$ \\
\hline $\begin{array}{l}\text { Çevrimiçi } \\
\text { Pazarlama } \\
\text { İletişimi }\end{array}$ & 1 & Journal of Marketing Channels & Dapko ve Artis, 2014 \\
\hline $\begin{array}{l}\text { Çoklu Kanal } \\
\text { Pazarlaması }\end{array}$ & 1 & $\begin{array}{l}\text { Journal of Direct, Data and } \\
\text { Digital Marketing Practice }\end{array}$ & Ridley-Siegert, 2016 \\
\hline \multirow[t]{6}{*}{$\begin{array}{l}\text { Dijital } \\
\text { Pazarlama }\end{array}$} & \multirow[t]{6}{*}{6} & $\begin{array}{l}\text { Asian Journal of Business } \\
\text { Research, Baltic Journal of } \\
\text { Management }\end{array}$ & $\begin{array}{l}\text { Balasudarsun, Sathish } \\
\text { ve Gowtham, } 2018\end{array}$ \\
\hline & & $\begin{array}{l}\text { International Journal of Applied } \\
\text { Business and Economic } \\
\text { Research }\end{array}$ & $\begin{array}{l}\text { Khan, Rehman, Khan ve } \\
\text { Khan, } 2016\end{array}$ \\
\hline & & Journal of Consumer Marketing & $\begin{array}{l}\text { Hamilton, Kaltcheva ve } \\
\text { Rohm, } 2016\end{array}$ \\
\hline & & $\begin{array}{l}\text { Journal of Direct, Data and } \\
\text { Digital Marketing Practice }\end{array}$ & $\begin{array}{l}\text { Abrahams, Chaudhary } \\
\text { ve Deane, } 2010\end{array}$ \\
\hline & & $\begin{array}{l}\text { Journal of Marketing } \\
\text { Communications }\end{array}$ & Kumar ve Salo, 2018 \\
\hline & & $\begin{array}{l}\text { Journal of Research in } \\
\text { Interactive } \\
\text { Marketing }\end{array}$ & $\begin{array}{l}\text { Rohm, Kaltcheva ve } \\
\text { Milne, } 2013\end{array}$ \\
\hline \multirow[t]{2}{*}{$\begin{array}{l}\text { Dijital } \\
\text { Reklamcılık }\end{array}$} & \multirow[t]{2}{*}{2} & $\begin{array}{l}\text { International Journal of } \\
\text { Electronic Commerce }\end{array}$ & $\begin{array}{l}\text { Melville, Stevens, Plice } \\
\text { ve Pavlov, } 2006\end{array}$ \\
\hline & & $\begin{array}{l}\text { International Journal of Recent } \\
\text { Technology and Engineering }\end{array}$ & Sankar, 2019 \\
\hline \multirow{4}{*}{$\begin{array}{l}\text { Doğrudan } \\
\text { Pazarlama }\end{array}$} & \multirow[t]{4}{*}{4} & Interactive Marketing & Gaskill ve Hackett, 2001 \\
\hline & & $\begin{array}{l}\text { Journal of Direct, Data and } \\
\text { Digital Marketing Practice }\end{array}$ & Jain ve Reed, 2013 \\
\hline & & $\begin{array}{l}\text { Journal of Targeting, } \\
\text { Measurement and Analysis for } \\
\text { Marketing }\end{array}$ & $\begin{array}{l}\text { Chittenden ve Rettie, } \\
2003\end{array}$ \\
\hline & & Publishing research quarterly & Goff, 2011 \\
\hline
\end{tabular}


Cetin, C., Tiltay, M. A.

DEÜ SBE Dergisi,

Cilt: 23, Sayz: 4

\begin{tabular}{|c|c|c|c|}
\hline \multirow[t]{3}{*}{ E-Ticaret } & 3 & $\begin{array}{l}\text { Asia Pacific Journal of } \\
\text { Marketing and Logistics }\end{array}$ & $\begin{array}{l}\text { Reimers, Chao } \\
\text { Gorman, } 2016\end{array}$ \\
\hline & & Journal of Business Research & $\begin{array}{l}\text { Ellis-Chadwick } \\
\text { Doherty, } 2012\end{array}$ \\
\hline & & $\begin{array}{l}\text { Journal of Global Information } \\
\text { Management }\end{array}$ & Lin, Li ve Wang, 2015 \\
\hline $\begin{array}{l}\text { Elektronik } \\
\text { İletişim }\end{array}$ & 1 & Interactive Marketing & Malcolm, 2004 \\
\hline \multirow{4}{*}{$\begin{array}{l}\text { Hedef } \\
\text { Odakhl } \\
\text { Promosyon } \\
\text { İliskisel } \\
\text { Pazarlama }\end{array}$} & 1 & Management Science & $\begin{array}{lcc}\text { Sahni, } & \text { Zou } & \text { ve } \\
\text { Chintagunta, } 2016 & \end{array}$ \\
\hline & 3 & $\begin{array}{l}\text { Cornell Hotel and Restaurant } \\
\text { Administration Quarterly }\end{array}$ & $\begin{array}{l}\text { Marinova, Murphy ve } \\
\text { Massey, 2002 }\end{array}$ \\
\hline & & $\begin{array}{l}\text { International Journal of Sport } \\
\text { Management and Marketing }\end{array}$ & Klenosky ve Brey, 2010 \\
\hline & & $\begin{array}{l}\text { Journal of Global Information } \\
\text { Management }\end{array}$ & Lin, Li ve Wang, 2015 \\
\hline $\begin{array}{l}\text { İlişkisel } \\
\text { Pazarlama } \\
\text { Stratejileri }\end{array}$ & 1 & $\begin{array}{lr}\text { International Journal Electronic } \\
\text { Customer } & \text { Relationship } \\
\text { Management } & \end{array}$ & Narayanaswamy, 2016 \\
\hline $\begin{array}{l}\text { Interaktif } \\
\text { Pazarlama }\end{array}$ & 1 & Journal of Marketing Research & $\begin{array}{l}\text { Kumar, Zhang ve Luo, } \\
2014\end{array}$ \\
\hline \multirow[t]{5}{*}{$\begin{array}{l}\text { İnternet } \\
\text { Pazarlaması }\end{array}$} & \multirow[t]{5}{*}{5} & $\begin{array}{l}\text { International Journal of Recent } \\
\text { Technology and Engineering }\end{array}$ & 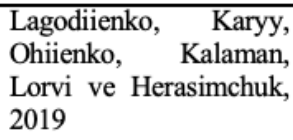 \\
\hline & & Internet Research & $\begin{array}{l}\text { Moustakas, } \\
\text { Ranganathan } \\
\text { Duquenoy, } 2006\end{array}$ \\
\hline & & Journal of Database Marketing & $\begin{array}{l}\text { Waring ve Martinez, } \\
2002\end{array}$ \\
\hline & & $\begin{array}{l}\text { Journal of Research in } \\
\text { Interactive Marketing }\end{array}$ & Hartemo, 2016 \\
\hline & & Management Science & $\begin{array}{l}\text { Sahni, } \quad \text { Zou } \\
\text { Chintagunta, } 2016\end{array}$ \\
\hline \multirow{4}{*}{$\begin{array}{l}\text { İnternet } \\
\text { Pazarlaması } \\
\text { Stratejileri }\end{array}$} & 4 & Contemporary Logistics & Liu, 2012 \\
\hline & & $\begin{array}{lrr}\text { International } & \text { Journal } & \text { of } \\
\text { Electronic } & \text { Marketing } & \text { and } \\
\text { Retailing } & & \end{array}$ & Utkarsh ve Gupta, 2019 \\
\hline & & Journal of Marketing Channels & Dapko ve Artis, 2014 \\
\hline & & $\begin{array}{l}\text { Journal of Marketing } \\
\text { Management }\end{array}$ & $\begin{array}{l}\text { Watjatrakul ve Drennan, } \\
2005\end{array}$ \\
\hline
\end{tabular}


E-Posta Pazarlaması Alanında...

DEU Journal of GSSS,

Vol: 23, Issue: 4

\begin{tabular}{|c|c|c|c|}
\hline \multirow{2}{*}{$\begin{array}{l}\text { Izinli } \\
\text { Pazarlama }\end{array}$} & \multirow[t]{2}{*}{2} & International Journal Sport & Klenosky ve Brey, 2010 \\
\hline & & Journal of Marketing Research & $\begin{array}{l}\text { Kumar, Zhang ve Luo, } \\
2014\end{array}$ \\
\hline \multirow[t]{4}{*}{$\begin{array}{l}\text { Mobil } \\
\text { Pazarlama }\end{array}$} & \multirow[t]{4}{*}{4} & Electron Markets & $\begin{array}{l}\text { Reichhart, Pescher ve } \\
\text { Spann, 2013 }\end{array}$ \\
\hline & & International Journal of & Waheed ve Yang, 2017 \\
\hline & & $\begin{array}{l}\text { Journal of Business Economics } \\
\text { and Management }\end{array}$ & $\begin{array}{l}\text { Ahmed, Vveinhardt ve } \\
\text { Streimikiene, } 2017\end{array}$ \\
\hline & & $\begin{array}{l}\text { Journal of Direct, Data and } \\
\text { Digital Marketing Practice }\end{array}$ & Ridley-Siegert, 2016 \\
\hline \multirow[t]{2}{*}{$\begin{array}{l}\text { Müșteri } \\
\text { İlișkileri }\end{array}$} & \multirow[t]{2}{*}{2} & $\begin{array}{l}\text { International Journal on } \\
\text { Customer Relations }\end{array}$ & Nath ve Gupta, 2013 \\
\hline & & Journal of Marketing Research & $\begin{array}{l}\text { Zhang, Kumar ve } \\
\text { Cosguner, } 2017\end{array}$ \\
\hline \multirow{2}{*}{$\begin{array}{l}\text { Müșteri } \\
\text { İlişkileri } \\
\text { Yönetimi } \\
\text { Müșteri } \\
\text { İlişkileri } \\
\text { Pazarlaması }\end{array}$} & 1 & $\begin{array}{l}\text { Journal of Global Information } \\
\text { Management }\end{array}$ & Lin, Li ve Wang, 2015 \\
\hline & 1 & $\begin{array}{l}\text { International Journal on } \\
\text { Customer Relations }\end{array}$ & Nath ve Gupta, 2013 \\
\hline \multirow[t]{8}{*}{$\begin{array}{l}\text { Pazarlama } \\
\text { Iletişimi }\end{array}$} & \multirow[t]{8}{*}{8} & $\begin{array}{l}\text { Asian Journal of Business } \\
\text { Research }\end{array}$ & $\begin{array}{l}\text { Balasudarsun, Sathish } \\
\text { ve Gowtham, } 2018\end{array}$ \\
\hline & & Cornell Hospitality Quarterly & O'Connor, 2008 \\
\hline & & $\begin{array}{l}\text { Industrial } \\
\text { Management }\end{array}$ & $\begin{array}{l}\text { Clarke, Flaherty ve } \\
\text { Zugelderc, 2005 }\end{array}$ \\
\hline & & Interactive Marketing & Anderson, 2003 \\
\hline & & $\begin{array}{l}\text { Journal of Electronic Commerce } \\
\text { in Organizations }\end{array}$ & $\begin{array}{l}\text { Hartemo, Suomi ve } \\
\text { Hakala, 2016 }\end{array}$ \\
\hline & & $\begin{array}{l}\text { Journal of Promotion } \\
\text { Management }\end{array}$ & Perry ve Shao, 2003 \\
\hline & & Journal of Real Estate Literature & $\begin{array}{l}\text { Acharya, Kagan ve } \\
\text { Zimmerman, } 2010\end{array}$ \\
\hline & & Market-Tržište & $\begin{array}{l}\text { Biloš, Turkalj ve Kelić, } \\
2016\end{array}$ \\
\hline \multirow[t]{3}{*}{$\begin{array}{l}\text { Pazarlama } \\
\text { Stratejileri }\end{array}$} & \multirow[t]{3}{*}{8} & Journal of Business Research & $\begin{array}{l}\text { Pavlov, Melville } \\
\text { Plice, 2008 }\end{array}$ \\
\hline & & $\begin{array}{l}\text { Journal of Direct, Data and } \\
\text { Digital Marketing Practice }\end{array}$ & Kucuk, 2011 \\
\hline & & $\begin{array}{l}\text { Journal of Direct, Data and } \\
\text { Digital Marketing Practice }\end{array}$ & Jain ve Garg, 2014 \\
\hline
\end{tabular}


Cetin, C., Tiltay, M. A.

DEÜ SBE Dergisi,

Cilt: 23, Sayz: 4

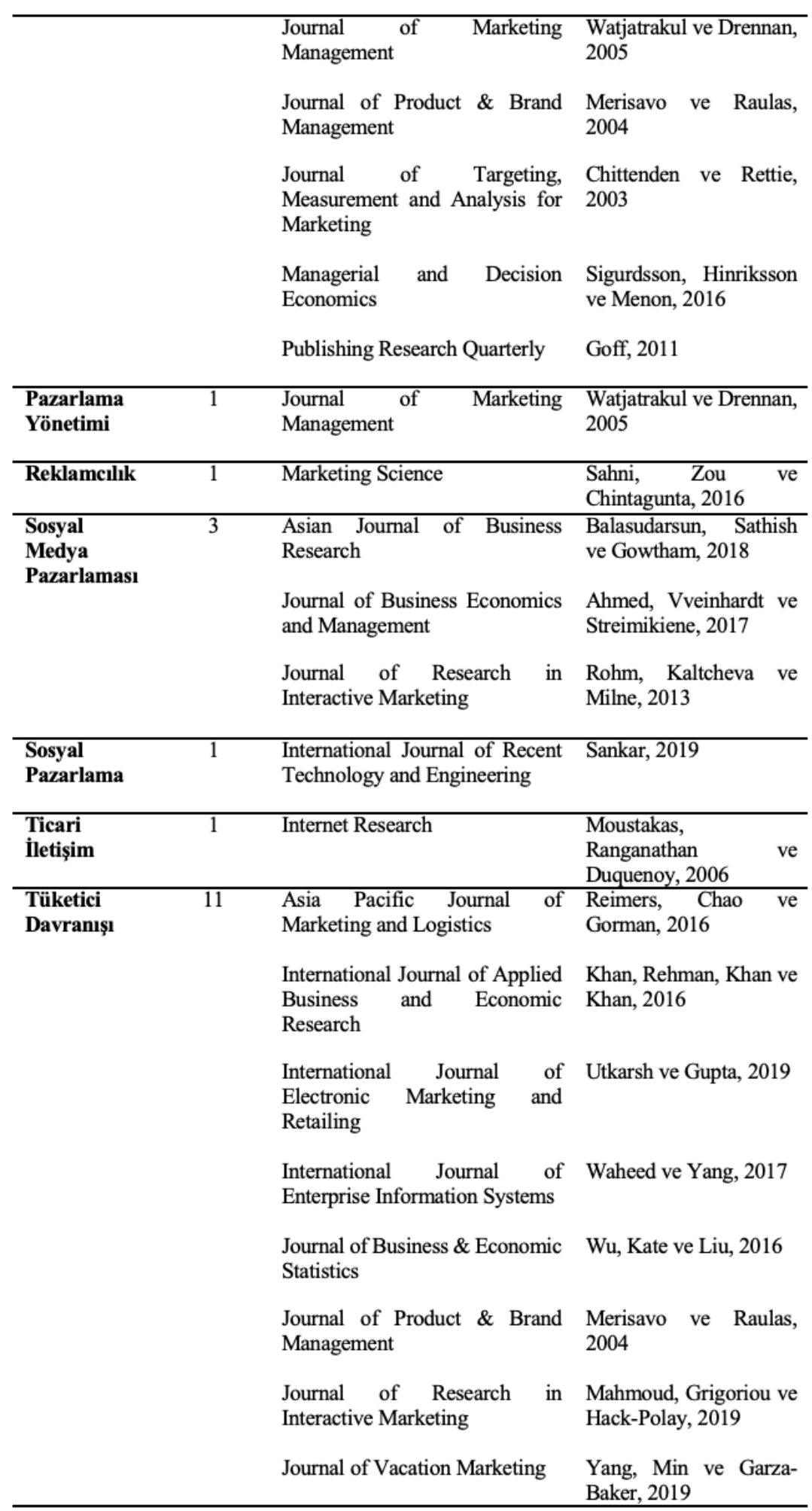


E-Posta Pazarlaması Alanında...

DEU Journal of GSSS,

Vol: 23, Issue: 4

\begin{tabular}{|c|c|c|c|}
\hline & & $\begin{array}{l}\text { Managerial and Decision } \\
\text { Economics }\end{array}$ & $\begin{array}{l}\text { Sigurdsson, Hinriksson } \\
\text { ve Menon, } 2016\end{array}$ \\
\hline & & Marketing Science & $\begin{array}{l}\text { Sahni, Wheeler ve } \\
\text { Chintagunta, } 2018\end{array}$ \\
\hline & & The Psychological Record & $\begin{array}{l}\text { Sigurdsson, Menon, } \\
\text { Sigurdarson, Foxall ve } \\
\text { Kristjansson, } 2013\end{array}$ \\
\hline $\begin{array}{l}\text { Tüketici } \\
\text { Deneyimi }\end{array}$ & 1 & Journal of Consumer Marketing & $\begin{array}{l}\text { Hamilton, Kaltcheva ve } \\
\text { Rohm, } 2016\end{array}$ \\
\hline $\begin{array}{l}\text { Tüketici } \\
\text { Güçlendirme }\end{array}$ & 1 & $\begin{array}{l}\text { Journal of Research in } \\
\text { Interactive Marketing }\end{array}$ & Hartemo, 2016 \\
\hline $\begin{array}{l}\text { Tüketici } \\
\text { İçgörüsü }\end{array}$ & 1 & Baltic Journal of Management & $\begin{array}{l}\text { Waheed ve Jianhua, } \\
2018\end{array}$ \\
\hline $\begin{array}{l}\text { Tüketici } \\
\text { İletişimi }\end{array}$ & 2 & $\begin{array}{l}\text { Journal of Database Marketing } \\
\text { Journal of Research in } \\
\text { Interactive Marketing }\end{array}$ & $\begin{array}{l}\text { Waring ve Martinez, } \\
2002 \\
\text { Rohm, Kaltcheva ve } \\
\text { Milne, } 2013\end{array}$ \\
\hline $\begin{array}{l}\text { Veri Tabanlı } \\
\text { Pazarlama }\end{array}$ & 2 & $\begin{array}{l}\text { Interactive Marketing } \\
\text { Journal of Direct, Data and } \\
\text { Digital Marketing Practice }\end{array}$ & $\begin{array}{l}\text { Stevens, } 2004 \\
\text { Reed ve Jain, } 2015\end{array}$ \\
\hline $\begin{array}{l}\text { Viral } \\
\text { Pazarlama }\end{array}$ & 1 & Interactive Marketing & Anderson, 2003 \\
\hline $\begin{array}{l}\text { Web } \\
\text { Reklamcılığı }\end{array}$ & 1 & Journal of Business Research & $\begin{array}{l}\text { Ellis-Chadwick } \\
\text { Doherty, } 2012\end{array}$ \\
\hline
\end{tabular}


Çetin, C., Tiltay, M. A. DEÜ SBE Dergisi,

Cilt: 23, Sayı: 4

Tablo 7: E-Posta Pazarlaması Çalışmalarına Genel Toplu Bir Bakıș

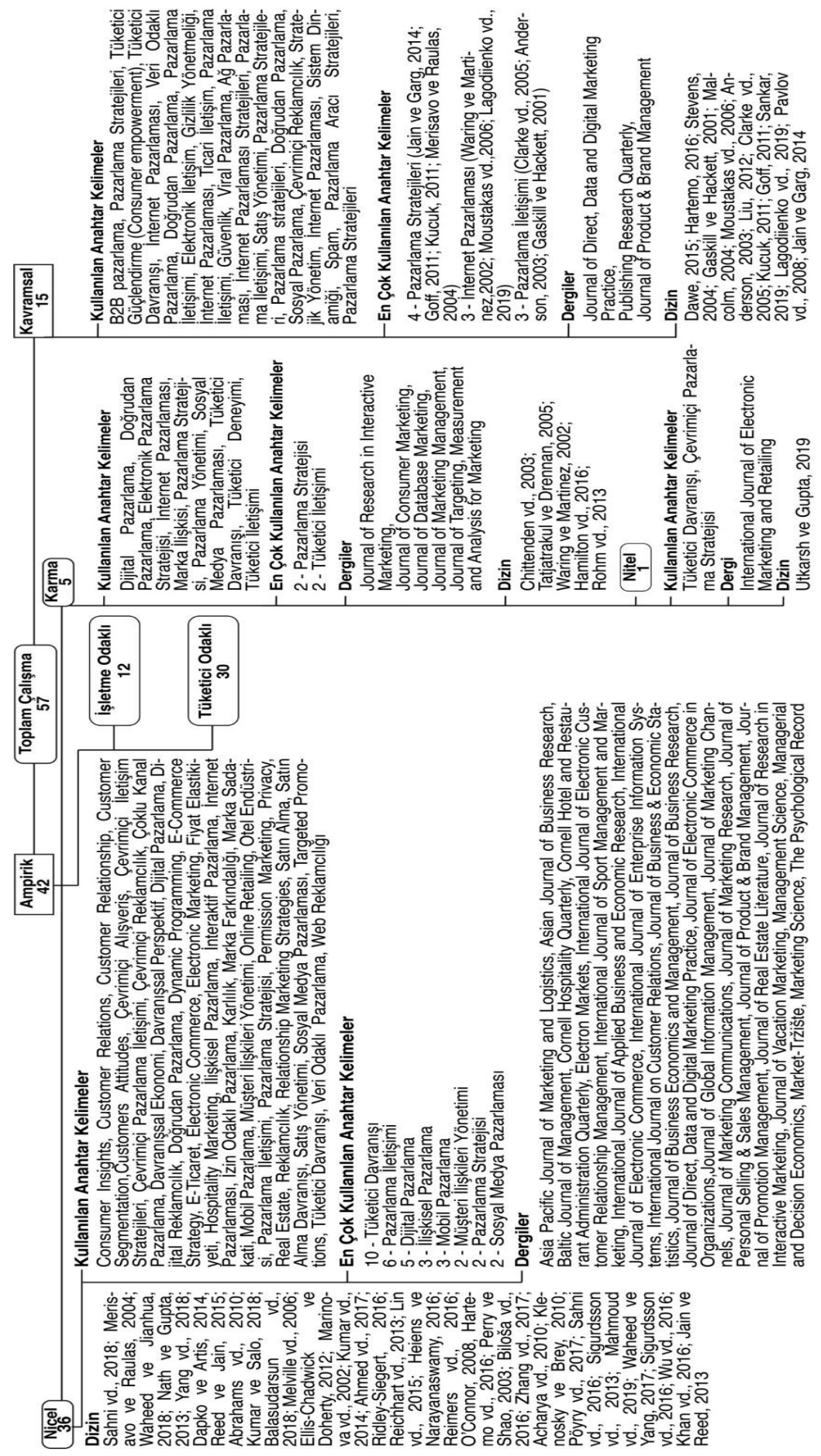


Tablo 7'den, gerçekleştirilmiş literatür taramasında yer alan çalışmaların yöntemlerine, analiz seviyelerine ve dizinlerine dair genel bir görünüm elde edilebilmektedir.

\section{Ampirik E-Posta Pazarlaması Çalışmalarının Yöntemleri, Veri Toplama Araçları ve Analiz Birimleri}

İncelenen çalışmalar ampirik ve kavramsal olarak iki sınıfa ayrılmıştır. Ampirik çalışmaların \%86'sı nicel, \%12'si karma ve \%2'si nitel yöntemle gerçekleştirilmiştir.

Grafik 2: Ampirik E-Posta Çalışmalarının Yöntem Türlerine Göre Yüzdelik Dağılımı

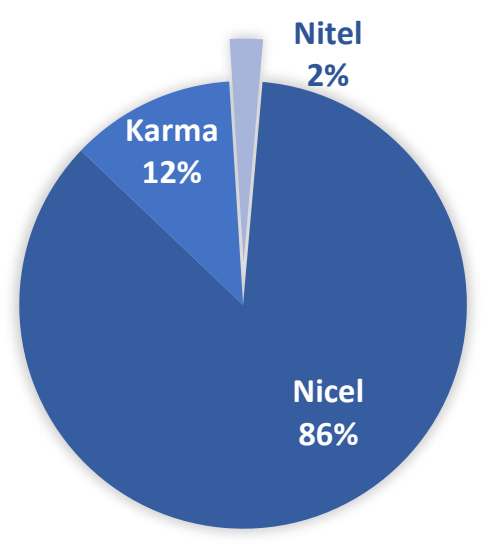

Grafik 2'den de görüldüğü üzere, taranan alanda nicel çalışmalar yoğunluktadır. Hanson \& Grimmer (2007) tarafindan 1993-2002 yılları arasındaki pazarlama çalışmalarında kullanılan yöntemlerin yoğunluklarının incelendiği çalışmada, literatürdeki çalışmaların \% 70 'ten fazlasının nicel yöntem ile gerçekleştirildiği görülmüştür. Kapsam dahilinde ulaştığımız ilk e-posta pazarlama araştırmasının 2001 yılında olması, Hanson \& Grimmer'ın çalışmasındaki tarih aralığının devamını niteliğinde, e-posta pazarlaması ölçeğinde genişletilebilecektir. Ulaşılan \%86'lık nicel araştırma yoğunluğu ise pazarlama alanının genel incelenmesinde ve özele inildiğinde nicel araştırmaların popülerliğini koruduğunu göstermektedir.

Ampirik çalışmalar ele alındığında kullandıkları veri toplama yöntemlerinin de birbirinden farklılaştı̆ğ görülmüş̧ür. Grafik 3'ten görüldüğü üzere çalışmaların $\% 41$ 'inde veriler anket ile toplanmışken, \%21'i ikincil veri ve deney tasarımı ile elde edilmiştir. 
Grafik 3: E-Posta Pazarlaması Çalışmalarının Veri Toplama Araçlarına Göre Yüzdelik Dağılımı

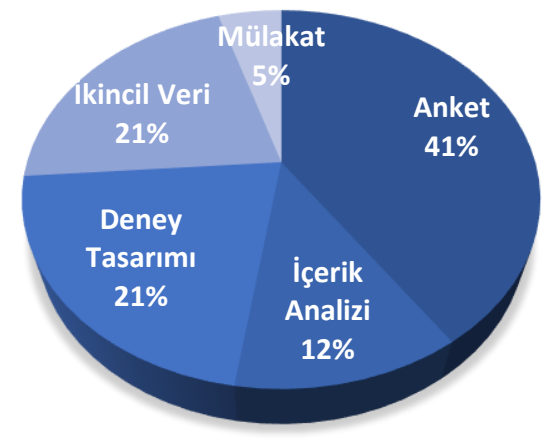

\%86 oranında öne, çıkan nicel yöntemle gerçekleştirilen çalışmaların veri toplama araçları incelendiğinde; anketin öne çıkan veri toplama yöntemidir. Anketle veri toplama, pazarlama çalışmalarında en çok kullanılan yöntemdir (Hair vd., 2008). Bu durumun sebepleri arasında internet üzerinden kolay ve hizlıca verinin toplanabilmesi de yer almaktadır (Gosling vd., 2004). Deney tasarımı ise bir yapının başka bir yapının oluşumuna dahil olma veya olmama durumunu araştırmanın en iyi yolu olduğundan (Aronson vd., 1990), deney tasarımının nedensel ilişkileri ortaya çıkarmak için geliştirildiği söylenebilmektedir (Doğan, 2019). İncelediğimiz literatürdeki çalışmaların \%21'inin deney tasarımı ile gerçekleştirilmesi, bu araştırmaların nedensellik üzerine gerçekleştirildiğini göstermektedir. \%21 oranında yer alan ikincil veri kullanımı ise hem nicel hem de nitel yöntemler ile kullanılabilmektedir (Witkowski \& Jones, 2006). Pazarlama araştırmalarında ikincil veri, pazarlama stratejilerinin tasarlanmasında, tüketici alışkanlıklarında ve geçmiş deneyimler hakkında bilgi edinmek üzere kullanılmaktadır (Harrison \& Reilly, 2011). Literatürde ele alınan e-posta pazarlaması çalışmalarına bakıldığında ikincil verinin kullanımının daha çok pazarlama stratejileri ve tüketici alışkanlıkları üzerine gerçekleştirildiği görülebilmektedir. 
Grafik 4: E-Posta Pazarlaması Çalışmalarının Analiz Birimlerine Göre Yüzdelik Dağılımı

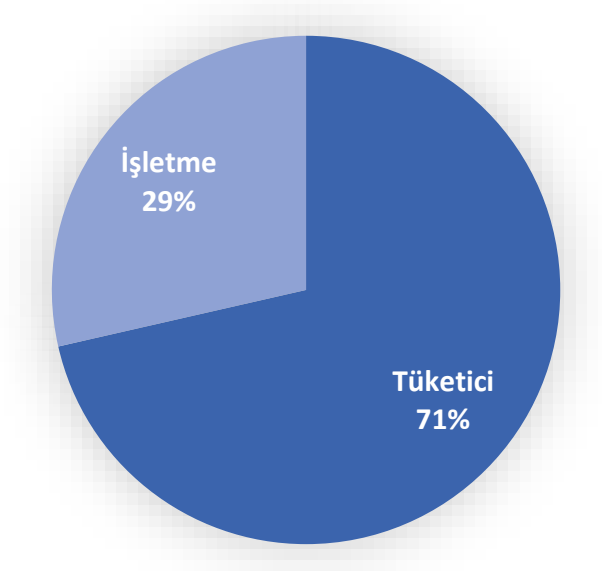

Literatürde gerçekleştirilen ampirik çalışmaların analiz birimlerine göre incelenmelerinin sonucunda (Grafik 4.) \%71'e eşdeğer olan 30 çalışmanın tüketici odaklı, geri kalan 12 çalışmanın oluşturduğu \%29'un ise işletme odaklı olduğuna ulaşılmıştır. Grafik ve alandaki çalışmalar ele alındığında, tüketicilere dair öngörünün sağlanmasına daha çok odaklanıldığı, işletmelere yönelik çalışmalarda yasalar, güvenlik ve verimlilik artışının sağlanabilmesine değinildiği söylenebilmektedir. E-posta pazarlaması ile elde edilen \%80'in üzerinde geri dönüş oranına sahip olunabilmesi (Emarsys, 2018) ile literatürde gerçekleştirilmiş olan tüketiciye yönelik çalışmalar arasında bir bağlantı kurulması da mümkündür.

Tablo 8: Analiz Birimlerine Göre E-Posta Pazarlaması Çalışmaları İşletme Odaklı:

Abrahams vd., 2010; Acharya vd., 2010; Chittenden \& Rettie, 2003; Ellis-Chadwick \& Doherty, 2012; Heiens \& Narayanaswamy, 2016; Melville vd., 2006; Nath \& Gupta, 2013; Ahmedi vd., 2016; O'Connor, 2008; Perry \& Shao, 2003; Waring \& Martinez, 2002; Watjatrakul \& Drennan, 2005; Zhang vd., 2017.

\section{Tüketici Odaklı:}

Ahmedi vd., 2016; Balasudarsun vd., 2018; Biloš vd., 2016; Dapko \& Artis, 2014; Hamilton vd., 2016; Hartemo vd., 2016; Jain \& Reed, 2013; Khan vd., 2016; Klenosky \& Brey, 2010; Kumar \& Salo, 2018; Kumar vd., 2014; Lin vd., 2015; Mahmoud vd., 2019; Marinova vd., 2002; Pöyry vd., 2017; Reed \& Jain, 2015; Reichhart vd., 2013; Reimers vd., 2016; Ridley-Siegert, 2016; Rohm vd., 2013; Sahni vd., 2016; Sahni vd., 2016; Sigurdsson vd., 2016; Sigurdsson vd., 2013; Utkarsh \& Gupta, 2019; Waheed \& Yang, 2017; Wu vd., 2016. 


\section{SONUÇ, TARTIŞMA VE ÖNERILER}

Yazın taramaları en genel kapsamıyla halihazırda literatürde yer alan çalışmaların değerlendirmeleridir (Bem, 1995). Şematik yazın taraması olarak gerçekleştirilen bu çalışma, yazın taramalarının hedeflerinden biri olan: "konu çerçevesinde mevcut duruma ilişkin sentezlenmiş bir genel bakış sağlamak" (Palmatier vd., 2018) adına gerçekleştirilmiştir. Şematik literatür taraması ile e-posta pazarlaması literatüründeki boşlukların tablolar, grafikler ve sayılarla belirlenmesi bu alanda çalışmak isteyen araştırmacılara içgörü sağlayacaktır. Araştırma alanını tanımlamanın yanı sıra, tüm çalışmaların veya sadece bir alt grubun incelenmesine olanak sağlar. Aynı zamanda alanın incelemeye değer olup olmadığına dair mevcut kaynakları yansıtarak önizleme sunar. Bu nedenle literatürün haritasını çıkarmak sonraki çalışmalar için önem taşımaktadır. Çalışma ile e-posta pazarlaması alanında çalışmak isteyen araştırmacılara alana dair detaylı ve alanı anlamalarına yardımcı olacak bir içgörü sunulmaktadır.

E-posta pazarlaması literatürü 1950-2019 yılları ve yalnızca pazarlama çalışmaları kapsamında ele almıştır. İncelenmiş olan literatürün seçiminde, çevrim içi pazarlamanın en etkin iletişim araçlarından biri olan e-posta pazarlaması (Hudák vd., 2017) ele alınarak alana dair genel bir bakışın oluşturulması hedeflenmiştir. Otelcilikten (O'Connor, 2008; Yang vd., 2018), perakendeciliğe (Heiens \& Narayanaswamy, 2016), bankacilık (Nath \& Gupta, 2013), yayımcılık (Goff, 2011), emlakçılığa (Acharya vd., 2010) kadar birçok sektörde çalışmaların yer alması eposta pazarlamasının kapsamının büyüklüğü hakkında bir ipucu niteliğindedir.

Araştırma, belirlenen anahtar kelimeler ("e-mail marketing", "email marketing") aracılığıyla ulaşılmış olan e-posta pazarlaması çalışmalarının kapsamlı bir literatür taramasını ve 1950-2019 yılları arasında yayınlanmış olan 57 çalışmaya dair bir sınıflandırma sistemi sunmaktadır. Çalışmalar Grant \& Booth (2009) ve Gough ve arkadaşları (2006) tarafindan sunulan öneriler dikkate alınarak Littell ve arkadaşlarının (2008) kullandığı yol izlenerek konularına, yöntemlerine, veri toplama araçlarına, analiz birimlerine, yer aldıkları elektronik veri tabanlarına ve yayınlandıkları dergilere göre sınıflandırılmıştır.

İlk e-posta pazarlamasına dair çalışmanın 2001 yılında görülmüş olması tüm dünyada 1995 yılında yalnızca 2 milyon e-posta hesabının bulunması ve 2001 yılının başında ise 891 milyon hesaba yükselmiş olması (Chittenden \& Rettie, 2003) ile ilişkilendirilebilmektedir. Hızlı artan e-posta kullanıcı sayısı ve kullanımı, yeni ortaya çıkan ve hızlı büyüyen bir iletişim kanalı olarak dikkatleri üzerine çekerek cazip bir alan oluşturmuştur.

Ele alınan literatürde yer alan kavramsal çalışmalar; değer yaratma (Kucuk, 2011), tüketicilerin tanınması (Jain \& Reed, 2013), B2B odağında kullanım (Dawe, 2015), uygulamacıların aracı verimli kullanmaları için öneriler (Stevens, 2004), yasalar ve mevzuat (Gaskill \& Hackett, 2001) ve satış gücüne etkileri (Clarke vd., 
2005) gibi alanlara değinerek e-posta pazarlaması kavramının güçlenmesine katkıda bulunmuştur.

Ampirik çalışmalar; e-ticaret (Ellis-Chadwick \& Doherty, 2012; Lin vd., 2005; Reimers vd., 2016), müşteri ilişkileri (Nath \& Gupta, 2013; Zhang vd., 2017), sosyal medya pazarlamas1 (Rohm vd., 2013; Ahmed vd., 2017; Balasudarsun vd., 2018) ve ilişkisel pazarlama (Marinova vd., 2002; Klenosky \& Brey, 2010; Lin vd., 2015) gibi alanlara yönelik gerçekleştirilerek genişlemeye yardımcı olmuştur. Kavramsal çalışmaların ampirik çalışmalara oranla daha az sayıda olması, kavramın güçlendirilmesi gerektiğinin göstergesi olabilirken akademisyenlere odaklanabilecekleri bir alan imkanı sunmaktadır.

Nicel araştırmaların literatürde baskın olmasının sebepleri; Kuhn (1973)'un belirttiği üzere pazarlama akademisyenlerin benzer eğitimlerden geçmeleri, aynı yöntem literatürünü benimsemeleri ve ortak bir yoldan ilerlemeleri ile ilişkilendirilebilmektedir. Hanson \& Grimmer (2007)'in nicel araştırmaları pazarlama disiplininde meşru görmesi, literatürdeki nicel araştırma yoğunluğunu açıklamaktadır. Elde edilen \%86'lık nicel araştırma yoğunluğu bu şekilde açıklanabilmektedir. Nitel çalışmaların araştırma sınırlarının daha geniş olması, sonuçların raporlanmasının uzun olması, savunulmasının ve güvenilirliğin sağlanmasının zorluğu (Martinsuo, 2001) gibi nedenler nitel araştırmaların nicel araştırmalardan daha az kullanılır olduğunun göstergesi olarak kabul edilebilir.

Sunulan sonuçların önemli etkileri bulunmaktadır:

- E-posta pazarlamasında en çok incelenen alan "tüketici davranışı"dır. "Pazarlama stratejileri” ve "pazarlama iletişimi" ise odaklanılan diğer konulardır. Günümüzde geleneksel medyanın önemini ve etkisini kaybetmesi kaybetmesi (Angelides, 1997), internet ve internet erişiminin önemini arttırmıştır. E-posta pazarlamasının internet kanalı ile gerçekleşmesi de dolaylı olarak e-posta pazarlamasının önemini yüksek oranda yükseltmektedir.

- E-posta pazarlaması halen akademisyenler ve uygulamacılar için üzerine fazla düşülmemiş bir alandır. Oluşturulan tablolardan e-posta pazarlaması alanında az sayıda çalışma bulunan niş konulara dair çıkarımlar yapılabilmektedir. Çalışılmış olan konuların farklılı̆̆ ve sayılarına bakılarak, incelenerek özellikle kavramsal çalışmalar ile geliştirilmeye açık olduğu görülmektedir. Az sayıda çalışma gerçekleştirilen konular ile ilgili alana katkı sağlama imkânı fazla olmaktadır.

- Gerçekleştirilmiş olan çalışmaların yayınlandığı akademik dergilerin statüsü göz önüne alındığında bu alanda yapılacak olan çalışmaların üst seviye dergilerde yer almaya açık olduğu çıkarımı yapılabilmektedir.

- Az sayıda ve birçok farklı konu özelinde çalışmanın gerçekleştirilmiş olması e-posta pazarlamasının yüzeysel olarak ele alındığını, derinlemesine ele alınması durumunda olumlu çıktılar verebileceğinin göstergesi olarak yorumlanabilmektedir.

Çalışmanın bulguları ve sonuçları bu alanda çalışmak isteyen araştırmacılara bazı öneriler sunmaktadır. B2B, çevrim içi alışveriş, çevrim içi pazarlama iletişimi, 
çoklu kanal pazarlaması, dijital reklamcılık, elektronik iletişim, hedef odaklı promosyon, interaktif pazarlama stratejileri, interaktif pazarlama, müşteri ilişkileri yönetimi, müşteri ilişkileri pazarlaması, pazarlama yönetimi, reklamcılık, sosyal pazarlama, ticari iletişim, tüketici deneyimi, tüketici güçlendirme, tüketici içgörüsü, viral pazarlama, web reklamcılığı konularında az sayıda çalışma gerçekleştirilmiş olması e-posta pazarlaması alanında çalışmak isteyen araştırmacılara bu çalışmanın ilk önerisidir.

Yöntemlerine göre çalışmalara bakıldığında nicel çalışmaların ezici üstünlüğü araştırmacılara nitel çalışmaların bu alanda eksik olduğunu göstermekte ve çalışmalarını nitel yöntemlerle gerçekleştirmelerini önermektedir.

Analiz birimleri bazında e-posta pazarlaması çalışmalarının büyük oranda tüketici odaklı gerçekleştirilmiş olması, işletme odaklı çalışma sayısının az olması, B2B kapsamında pratiğe yönelik çalışmaların gerçekleştirilmesini önerme noktasında etkili bir destektir.

E-posta pazarlamasının e-ticaretin en kritik araçlarından biri olması (Fariborzi ve Zahedifard, 2012) bu alanda çalışmanın ne kadar önemli olduğunu göstermektedir. Aynı zamanda e-ticaret faaliyetlerindeki büyük payı, firmalara olumlu geri dönüşler sağlaması (Hudak vd., 2017) bu alanda çalışacak araştırmacıların hem literatüre hem de pratiğe katkıda bulumalarını sağlayacaktır.

E-posta pazarlaması alanını ele alan bu şematik yazın tarama çalışması ile 1950-2019 yılları arasındaki e-posta pazarlaması çalışmalarına dair genel bir bakış sağlanması amaçlanmıştır. E-postaların kullanılmaya devam edilmesi sürdükçe bu alanın önemini kaybetmeyeceği ve özellikle e-ticaretteki öneminin sürecektir. Bu konu üzerine gerçekleştirilecek olan çalışmaların hem araştırmacıların hem de uygulamacıların dikkatini çekeceği ve iki alana da katkıda bulunacağ 1 düşünülmektedir.

\section{Araștırma Kısıtları}

Çalışma geçmiş ve geleceğe dönük e-posta pazarlamasına dair bakış açıları sunmakla birlikte bahsedilmesi gereken bazı kısıtlara sahiptir. İlk olarak incelenmiş olan elektronik veri tabanlarının bütün akademik dergilere erişime sahip olmamasıdır. Bu nedenle çalışma ABI/Inform, EBSCO (Business Source Premier) ve Scopus elektronik veri tabanlarının sunduğu içerik ile kısıtlı bir şekilde gerçekleştirilmiştir. İkinci olarak arama terimlerinin kapsayıcılığının sınırlılığ bulunmaktadır. Kullanılan anahtar kelimelerinin haricinde yer alan e-posta pazarlaması alanında gerçekleştirilmiş olan çalışmaların yer alması muhtemeldir. Üçüncüsü ise elektronik veri tabanında ele alınan dergilerin genelinin pazarlama odağında olmaları tercih edilmiş ve başka alanların odağında çalışmalara yer veren akademik dergiler ele alınmamıştır. 


\section{Araştırma, Yayın Etiği ve Telif Hakları Beyanı}

Gerçekleştirilen çalışmadaki tüm bilgi ve belgeler akademik kurallar çerçevesinde elde edilmiştir. Yararlanılan kaynaklara bilimsel normlara uygun olarak atıfta bulunularak, etik kurallara dayanarak gösterilen durumlar haricindeki tüm içerik özgün bir şekilde, fikir ve sanat eserleri için telif hakları düzenlemelerine uyularak üretilmiştir.

\section{KAYNAKÇA}

Abrahams, A. S., Chaudhary, T. \& Deane, J. K. (2010). A multi-industry, longitudinal analysis of the email marketing habits of the largest United States franchise chains. Journal of Direct, Data and Digital Marketing Practice, 11 (3), 187-197.

Acharya, R., Kagan, A. \& Zimmerman, T. (2010). Real estate information technology: Influence of email marketing on real estate agent performance. Journal of Real Estate Literature, 18 (2), 329-343.

Ahmed, R. R., Vveinhardt, J. \& Streimikiene, D. (2017). Interactive digital media and impact of customer attitude and technology on brand awareness: evidence from the South Asian countries. Journal of Business Economics and Management, 18 (6), 1115-1134.

Alalwan, A. A., Rana, N. P., Dwivedi, Y. K., \& Algharabat, R. (2017). Social media in marketing: A review and analysis of the existing literature. Telematics and Informatics, 34 (7), 1177-1190.

Anderson, J. (2003). New Technology Briefing: Video e-mail-The next generation of e-mail marketing?. Interactive Marketing, 4 (3), 281-284.

Balasudarsun, N. L., Sathish, M. \& Gowtham, K. (2018). Optimal ways for companies to use Facebook Messenger Chatbot as a Marketing Communication Channel. Asian Journal of Business Research, 8 (2), 1.

Bem, D. J. (1995). Writing a review article for psychological bulletin. Psychological Bulletin, 118 (2), 172-177.

Biloš, A., Turkalj, D. \& Kelić, I. (2016). Open-rate controlled experiment in e-mail marketing campaigns. Market-Tržište, 28 (1), 93-109.

Chaffey, D., Mayer R., Johnston K. \& Ellis-Chadwick FE (2003). Businessto-business Internet marketing. D. Chaffey (Der.), Internet marketing: strategy, implementation and practice. Harlow, Essex: Pearson Education - China Machine Press. 
Chittenden, L. \& Rettie, R. (2003). An evaluation of e-mail marketing and factors affecting response. Journal of Targeting, Measurement and Analysis for Marketing, 11 (3), 203-217.

Cho, C. H. \& Khang, H. (2006). The state of Internet-related research in communications, marketing, and advertising: 1994-2003. Journal of Advertising 35 (3), 143-163.

Clarke III, I., Flaherty, T. B. \& Zugelder, M. T. (2005). The CAN-SPAM Act: New rules for sending commercial e-mail messages and implications for the sales force. Industrial Marketing Management, 34 (4), 399-405.

Dapko, J. L. \& Artis, A. B. (2014). Less is more: An exploratory analysis of optimal visual appeal and linguistic style combinations in a salesperson's initialcontact e-mail to millennial buyers within marketing channels. Journal of Marketing Channels, 21 (4), 254-267.

Dawe, K. (2015). Best practice in business-to-business email. Journal of Direct, Data and Digital Marketing Practice, 16 (4), 242-247.

DMA (2019). Marketer email tracker 2019. https://dma.org.uk/uploads/misc/marketers-email-tracker-2019.pdf (Erişim: 08.05.2020).

Doğan, V. (2019). Pazarlama araştırmacıları için deneysel tasarım: felsefi arka plan ve metodolojik tartı. Pazarlama Teorisi ve Uygulamaları Dergisi, 5 (1), $123-160$

DuFrene, D. D., Engelland, B. T., Lehman, C. M. \& Pearson, R. A. (2005). Changes in consumer attitudes resulting from participation in a permission e-mail campaign. Journal of Current Issues and Research in Advertising 27 (1), 65-77.

Ellis-Chadwick, F. \& Doherty, N. F. (2012). Web advertising: The role of email marketing. Journal of Business Research, 65 (6), 843-848.

Emarsys (2018). Adapting to the pace of omnichannel commerce. https://emarsys.com/wp-content/uploads/2018/01/eTail-Emarsys-WBR-SMBReport.pdf (Erişim: 08.05.2020).

Farhoomand, A. \& Lovelock, P. (2001). Global e-Commerce. Singapore: Prentice-Hall.

Fariborzi, E., \& Zahedifard, M. (2012). E-mail Marketing: Advantages, Disadvantages andImproving Techniques. International Journal of e-Education, eBusiness, e-Management and e-Learning, 2(3), 232.

Gaskill, S. \& Hackett, A. (2001). E-mail and text message marketing. Interactive Marketing, 3 (2), 160-165. 
Goff, N. (2011). Direct-response bookselling: How it died, why it is alive again, and why it will become even more important in the future. Publishing Research Quarterly, 27 (3), 259.

Gosling, S. D., Vazire, S., Srivastava, S. \& John, O. P. (2004). Should we trust web-based studies? A comparative analysis of six preconceptions about internet questionnaires. American Psychologist, 59 (2), 93-104.

Gough, D., Kiwan, D., Suttcliffe, K., Simpson, D., \& Houghton, N. (2006). A systematic map and synthesis review of the effectiveness of personal development planning for improving student learning. EPPI-Centre, 1 (1), 1-127.

Gratton, E. (2003). Internet and wireless privacy: a legal guide to global business practices. Toronto: CCH Canadian Limited.

Green, B. N., Johnson, C. D., \& Adams, A. (2006). Writing narrative literature reviews for peer-reviewed journals: secrets of the trade. Journal of chiropractic medicine, 5 (3), 101-117.

Gupta, N. (2019). Message strategy of promotional e-mails in India: a content analysis. International Journal of Electronic Marketing and Retailing, 10 (4), 351-367.

Hair, J. F., Celsi, M., Ortinau, D. J. \& Bush, R. P. (2008). Essentials of marketing research. New York, NY: McGraw-Hill/Higher Education.

Hamilton, M., Kaltcheva, V. D. \& Rohm, A. J. (2016). Hashtags and handshakes: consumer motives and platform use in brand-consumer interactions. The Journal of Consumer Marketing, 33 (2), 135.

Harrison, R. L. \& Reilly, T. M. (2011). Mixed methods designs in marketing research. Qualitative Market Research: An International Journal, 14 (1), 7-26.

Hartemo, M. (2016). Email marketing in the era of the empowered consumer. Journal of Research in Interactive Marketing, 10 (3), 212-230.

Hartemo, M., Suomi, R. \& Hakala, U. (2016). Towards Improved Performance: A Model for Testing Email Newsletter Design. Journal of Electronic Commerce in Organizations (JECO), 14 (3), 1-16.

Heiens, R. A. \& Narayanaswamy, R. (2016). An examination of the e-mail and electronic relationship marketing practices of the USA's top 500 online retailers. International Journal of Electronic Customer Relationship Management, 10 (2-4), 125-137.

Hoge, C.C. (1993). The Electronic Marketing Manual. New York, NY: McGraw-Hill. 
Hudák, M., Kianičková, E., \& Madleňák, R. (2017). The importance of email marketing in e-commerce. Procedia engineering, 192, 342-347.

Internet World Stats (2020). Internet Users Distribution in the World 2020 Q1. https://www.internetworldstats.com/stats.htm (Erişim: 14.04.2020).

Jain, Y. \& Garg, R. (2014). National email benchmarking report 2013. Journal of Direct, Data and Digital Marketing Practice, 16 (2), 92-97.

Jain, Y. \& Reed, D. (2013). DMA print tracking: Attributes of media channels. Journal of Direct, Data and Digital Marketing Practice, 15 (1), 56-63.

Khan, S. F., Rehman, S., Khan, M. K. \& Khan, M. A. (2016). Influence of gender and nationality on consumers' perception towards email marketing: an exploratory study in Oman. International Journal of Applied Business and Economic Research, 14 (1), 457-464.

Kinnard, S. (2002). Marketing with e-mail: a spam-free guide to increasing sales, building loyalty, and increasing awareness. Toronto: Maximum Press.

Klenosky, D. B. \& Brey, E. T. (2010). Permission to promote: a conjoint investigation of e-newsletter preferences. International Journal of Sport Management and Marketing, 7 (3-4), 173-189.

Knight, G. (1999). International services marketing: review of research, 1980-1998. Journal of Services Marketing, 13 (4-5), 347-360.

Krishnamurthy, S. (2001). A comprehensive analysis of permission marketing. Journal of Computer Mediated Communication 6 (2): JCMC623.

Kucuk, S. U. (2011). Towards integrated e-marketing value creation process. Journal of Direct, Data and Digital Marketing Practice, 12 (4), 345-363.

Kuhn, T. (1973). The Structure of Scientific Revolutions. Chigago, IL: University of Chicago Press.

Kumar, A. \& Salo, J. (2018). Effects of link placements in email newsletters on their click-through rate. Journal of Marketing Communications, 24 (5), 535-548.

Kumar, V., Zhang, X. \& Luo, A. (2014). Modeling customer opt-in and optout in a permission-based marketing context. Journal of Marketing Research, 51(4), 403-419.

Lagodiienko V., Karyy O., Ohiienko, M., Kalaman, O., Lorvi, I. \& Herasimchuk, T. (2019). Choosing Effective Internet Marketing Tools in Strategic Management. International Journal of Recent Technology and Engineering (IJRTE), $8(3), 5220-5225$.

Lin, H. H., Li, H. T. \& Wang, Y. S. (2015). Permission-based e-mail marketing websites success: An integrated perspective. Journal of Global Information Management (JGIM), 23 (2), 1-23. 
Littell, J. H., Corcoran, J., \& Pillai, V. (2008). Systematic reviews and metaanalysis. New York: Oxford University Press.

Liu, H. (2012). The researches on e-mail marketing of small and mediumsized B2B enterprises. Contemporary Logistics, 6 (24).

Mahmoud, A., Grigoriou, N. \& Hack-polay, D. (2019). Email is Evil! Behavioural Responses towards Permission based Direct Email Marketing and Gender Differences. Journal of Research in Interactive Marketing, 213 (2), 227248.

Malcolm, W. (2004). Legal and Regulatory Update: E-mail marketing: How to do it lawfully. Interactive Marketing, 6 (2), 179-183.

Marinova, A., Murphy, J. \& Massey, B. L. (2002). Permission e-mail marketing as a means of targeted promotion. Cornell Hotel and Restaurant Administration Quarterly, 43 (1), 61-69.

Martinsuo, M. (2001), "Balancing large scope and project manageability in a qualitative research design", Management Decision, 39 (7), 539-550.

McCloskey W. (2006). E-mail data source. New York: Retail White Paper.

Melville, N., Stevens, A., Plice, R. K. \& Pavlov, O. V. (2006). Unsolicited commercial e-mail: Empirical analysis of a digital commons. International Journal of Electronic Commerce, 10 (4), 143-170.

Merisavo, M. \& Raulas, M. (2004). The impact of e-mail marketing on brand loyalty. Journal of Product \& Brand Management, 13 (7), 498-505.

Moustakas, E., Ranganathan, C. \& Duquenoy, P. (2006). E-mail marketing at the crossroads: A stakeholder analysis of unsolicited commercial e-mail (spam). Internet Research: Electronic Networking Applications and Policy, 16 (1), 38-52.

Nath, V. \& Gupta, N. (2013). Bank E-mail Marketing: Creating Customer Relations with Permission. International Journal on Customer Relations, 1 (2), 41.

Nettleton, E. (2005). Getting tough on spam? Database Marketing \& Customer Strategy Management, 12 (4), 357-61.

O'Connor, P. (2008). E-mail marketing by international hotel chains: An industry-practices update. Cornell Hospitality Quarterly, 49 (1), 42-52.

Pavlov, O. V., Melville, N. \& Plice, R. K. (2008). Toward a sustainable email marketing infrastructure. Journal of Business Research, 61 (11), 1191-1199.

Perry, M. L. \& Shao, A. T. (2002). Internet Marketing Communications in the Selling Process: A Global Study of Advertising Agencies' Use of E-Mail and Websites. Journal of Promotion Management, 9 (1-2), 17-29. 
Pomirleanu, N., Schibrowsky, J. A., Peltier, J. \& Nill, A. (2013). A review of internet marketing research over the past 20 years and future research direction. Journal of Research in Interactive Marketing, 7 (3), 166-181.

Pöyry, E., Parvinen, P. \& McFarland, R. G. (2017). Generating leads with sequential persuasion: should sales influence tactics be consistent or complementary?. Journal of Personal Selling \& Sales Management, 37 (2), 89-99.

Reed, D. \& Jain, Y. (2015). DMA email tracking report 2014. Journal of Direct, Data and Digital Marketing Practice, 16 (3), 184-192.

Reichhart, P., Pescher, C. \& Spann, M. (2013). A comparison of the effectiveness of e-mail coupons and mobile text message coupons for digital products. Electronic Markets, 23 (3), 217-225.

Reimers, V., Chao, C. W. \& Gorman, S. (2016). Permission email marketing and its influence on online shopping. Asia Pacific Journal of Marketing and Logistics, 28 (2), 308-322.

Ridley-Siegert, T. (2016). DMA Insight: Consumer email tracking report 2015. Journal of Direct, Data and Digital Marketing Practice, 17 (3), 163-169.

Rohm, A., Kaltcheva, V. D. \& Milne, G. R. (2013). A mixed-method approach to examining brand-consumer interactions driven by social media. Journal of Research in Interactive Marketing, 7 (4), 295-311.

Sahni, N. S., Wheeler, S. C. \& Chintagunta, P. (2018). Personalization in email marketing: The role of noninformative advertising content. Marketing Science, 37 (2), 236-258.

Sahni, N. S., Zou, D. \& Chintagunta, P. K. (2017). Do targeted discount offers serve as advertising? Evidence from 70 field experiments. Management Science, 63 (8), 2688-2705.

Sankar, V. S. (2019). Online Advertising and Its Effective Methods. International Journal of Recent Technology and Engineering (IJRTE), 8 (2S6), 735737.

Sigurdsson, V., Hinriksson, H., \& Menon, R. V. (2016). Operant behavioral economics for e-mail marketing: An experiment based on the behavioral perspective model testing the effectiveness of motivational operation, utilitarian and informational stimuli. Managerial and decision economics, 37 (4-5), 337-344.

Sigurdsson, V., Menon, R. V., Sigurdarson, J. P., Kristjansson, J. S. \& Foxall, G. R. (2013). A test of the behavioral perspective model in the context of an e-mail marketing experiment. The Psychological Record, 63 (2), 295-308.

Snyder, H. (2019). Literature review as a research methodology: An overview and guidelines. Journal of Business Research, 104, 333-339. 
Statista (2020). Number of e-mail users worldwide from 2017 to 2024. https://www.statista.com/statistics/255080/number-of-e-mail-usersworldwide/(Erişim: 08.05.2020).

Statista (2020). Number of sent and received e-mails per day worldwide from 2017 to 2023. https://www.statista.com/statistics/456500/daily-number-of-e-mailsworldwide/(Erişim: 08.05.2020).

Stevens, G. (2004). New Technology Briefing: Best practice technology options for optimal e-mail marketing. Interactive Marketing, 6 (1), 62-70.

Tafesse, W., \& Skallerud, K. (2017). A systematic review of the trade show marketing literature: 1980-2014. Industrial Marketing Management, 63, 18-30.

Waheed, A. \& Jianhua, Y. (2018). Achieving consumers' attention through emerging technologies: The linkage between e-marketing and consumers' exploratory buying behavior tendencies. Baltic Journal of Management, 13 (2), 209235 .

Waheed, A. \& Yang, J. (2017). The effect of mobile marketing and email marketing on exploratory information seeking (EIS) behavior of the consumers: Communication through wireless technologies. International Journal of Enterprise Information Systems (IJEIS), 13 (4), 76-89.

Waring, T. \& Martinez, A. (2002). Ethical customer relationships: A comparative analysis of US and French organisations using permission-based e-mail marketing. Journal of Database Marketing \& Customer Strategy Management, 10 (1), 53-69.

Watjatrakul, B. \& Drennan, J. (2005). Factors affecting e-mail marketing sourcing decisions: A transaction cost perspective. Journal of Marketing Management, 21 (7-8), 701-723.

Witowski, T. H. \& Jones, D. B. (2006). Qualitative historical research in marketing. Handbook of Qualitative Research Methods in Marketing, 70-82.

Wu, J., Li, K. J. \& Liu, J. S. (2018). Bayesian inference for assessing effects of email marketing campaigns. Journal of Business \& Economic Statistics, 36 (2), 253-266.

Yang, K., Min, J. H. \& Garza-Baker, K. (2019). Post-stay email marketing implications for the hotel industry: Role of email features, attitude, revisit intention and leisure involvement level. Journal of Vacation Marketing, 25 (4), 405-417.

Zhang, X., Kumar, V. \& Cosguner, K. (2017). Dynamically managing a profitable email marketing program. Journal of marketing research, 54 (6), 851866. 